\title{
EL PARADIGMA DIFUSIONISTA Y LA NEOLITIZACIÓN DE LA PENINNSULA IBERICA: UNA EXPLICACIÓN RECURRENTE
}

\author{
ISABEL RUBIO DE MIGUEL \\ $\mathrm{Dpt}^{\circ}{ }^{\circ}$ de Prehistoria y Arqueologia, UAM
}

\section{Resumen}

El paradigma difusionista ha sido utilizado como explicación en los estudios del Neolítico peninsular de fornta prácticamente continuada a partir de los inicios de la investigación en el siglo XIX. Desde los plan:teamientos tradicionales de los dos prineros tercios de nuestro siglo hasta la aparición de otros alternativos, ya en la década de los ochenta, se hallará siempre presente con distintos matices (mayor énfasis en la vía norteaficana, en un principio, o en las relaciones europeas despues) La revalorización de este paradigma se produce en momentos más recientes cono consecuencia de la aceptación del modelo del "frente de avan$\mathrm{ce}^{n}$ y de diversas posibilidades derivadas de la colonización o la aculturación. Otras explicaciones, en cambio. hacen hincapié en modelos como el de "capilaridad" que otorga un papel preponderante a las relaciones sociales intergrupales.

\section{Summary}

Diffusionism has been used as an explanation in the studies concerning the Neolithic of the Iberian Peninsula almost contiruously since the beginnings of research in XIXth century. From traditional approaches in the first two thirds of our century to the emergence of others atiernative in the eighties, it will be always present with different nuances (more emphasis on North African way at the beginning or on European relations later) It is remarkable that the reassessment of this paradigm takes place in recent time as a consequence of the acceptance of the "wave of advance" model and the several posibilities derived from colonization or acculturation. Other explanations, on the contrary, emphasize models like that of "capilarity" which confers a preponderant role to social relations anong human groups.

No parece necesario insistir demasiado en el éxito obtenido por el difusionismo como paradigma de la investigación en Prehistoria desde su formulación en el siglo pa- 
sado. Es cosa sabida que la interpretación de diversos procesos clave de la misma ha participado de la idea de difusión como una adecuada explicación a las variaciones espaciales y temporales. Paralelamente, la reacción representada por el particularismo histórico que implica la descripción minuciosa de todos los elementos de cada cultura, presupone que éstas constituyen una entidad única que debe ser entendida en sus propios términos. Hacia 1880, como recuerda B. Trigger $(1992,146)$, los problemas derivados de los resultados de la Revolución Industrial condujeron a un replanteamiento de las líneas de pensamiento en vigor como consecuencia de una creciente pérdida de confianza en los logros del ser humano.

Al concepto de cultura como forma de vida característica de grupos étnicos determinados se unió el rechazo a la idea de que las invenciones han podido producirse más de una vez, lo que inevitablemente llevó a la necesidad de las teorías difusionistas o migratorias para explicar el cambio cultural. De la misma manera, el interés se centró en las características asociadas a grupos étnicos particulares en detrimento de las generales de los estadios sucesivos de desarrollo cultural.

Las investigaciones filológicas de la segunda mitad del siglo XIX ejercieron una gran influencia en este sentido como demuestra la amplia utilización del concepto de "Kulturkreis" (provincia o círculo cultural) acuñado por Meyer en 1884 que caracterizará también a la escuela alemana de $F$ Ratzel. Estos planteamientos condujeron, en ocasiones, a la defensa de difusiones a escala mundial claramente desorbitadas, como en el caso de determinados investigadores británicos o a la de la superioridad racial de ciertos pueblos patente en la obra de G. Kossina y de otros autores de diversas procedencias.

Dejando aparte este tipo de planteamientos, lo cierto es que el concepto de cultura arqueológica, el empleo de los mapas de difusión y la difusión o la migración como explicación desprovistas de connotaciones raciales, tuvieron un rotundo éxito en el estudio de fenómenos como el megalítico que únicamente la obtención de dataciones absolutas vino a invalidar. No ha ocurrido lo mismo con el Neolítico europeo y desde luego con el peninsular.

Paradójicamente los estudios sobre los grupos neolíticos europeos, aún sin una definición clara, se inician con anterioridad a los del Próximo Oriente, área considerada tradicionalmente como el foco de irradiación de "novedades" y de aparición de la civilización por su temprano paso a la Historia según las divisiones convencionales. Bien es verdad que se trata de descubrimientos accidentales propiciados por causas de origen climático (sequias de 1853 y 1854 que provocaron la bajada de nivel de los lagos alpinos). pero me parece de especial interés resaltar que se trata, en algunos casos, de investigaciones llevadas a cabo con un espíritu más amplio que la simple catalogación de materiales con criterios tipológicos. Los poblados lacustres alpinos suministraron restos faunisticos y vegetales en abundancia como para propiciar análisis modélicos en su momento (mediados del siglo XIX), anteriores a los de cualquier otro lugar $\mathrm{A}$ los estudios de F. Keller sobre los yacimientos de la cultura de Cortaillod se unieron pronto los de L. Rütimeyer en 1862 sobre la fauna y los de $O$. Heer en 1866 sobre los restos botánicos hallados en los mismos. Ambos supusieron un hito en la investigación de las primeras 
especies domésticas europeas. Sin embargo, podríamos decir que este hecho quedó eclipsado por los posteriores trabajos llevados a cabo en el Próximo Oriente, una vez definido éste como foco originario, lo que condujo irremediablemente a buscar en esta región la explicación para determinadas cuestiones más o menos problemáticas observadas en el continente europeo. Pero este planteamiento no hubiera sido posibie sin el auge de las corrientes difusionistas.

Asi pues, el punto de partida para el estudio del Neolítico peninsular, al igual que para el del continente europeo en general, suele situarse en la determinación de su origen, premisa asumida prácticamente por la totalidad de la comunidad investigadora inćluso de forma implícita, al igual que la aloctonía de determinados componentes del proceso de neolitización que se desarrolla en la Península Ibérica. Evidentemente, ambas cuestiones se hallan intimamente relacionadas entre sí y con la problemática sobre la procedencia de las primeras especies domésticas halladas en los yacimientos peninsulares. La tésis de una autoctonía completa para el Neolítico de la Península Ibérica (y para el europeo) en sentido estricto no parece ser considerada firmemente por ningún investigador, por lo que el paso a las restantes cuestiones concomitantes ya citadas se produce con toda inmediatez. Otra cosa es que posiblemente se haya puesto demasiado énfasis en debatir los orígenes, caminos de llegada y procesos de adopción, relegando injustamente 0 por falta de datos los de la adaptación de los propios grupos peninsulares o el estudio de las diversas formas que reviste el acceso a los nuevos recursos alimenticios o a una distinta explotación del entorno por estas mismas gentes. Solamente en los últimos años aparecen explicaciones alternativas que toman en consideración cuestiones de este género.

Aún así, tales premisas han discurrido paralelas a la necesidad de establecer una cronología fiable, con todo el margen de variabilidad que puedan presentar las dataciones radiocarbónicas, cada vez más elevadas, cronología que adolece en todo caso de la falta de un mejor conocimiento de la duración de algunos grupos peninsulares lo que depende, consecuentemente, del grado de información que poseemos sobre cada una de las áreas sobre las que se asientan.

Sobre la historia de las investigaciones el lector hallará otras referencias en obras como la de M. ${ }^{\text {a }}$ S. Navarrete $(1976,17-24)$ o en la coordinada por P. Lopez (1988. 59-64) Además, los principales hitos experimentados por la investigación del Neolítico peninsular pueden encontrarse en una relativamente reciente obra de síntesis elaborada bajo este punto de vista (RUBio, 1991, 27-39). La historiografía propiamente dicha, tan del gusto actual, ha llegado también a los estudios del Neolítico peninsular, si bien se halla aún en sus inicios (MARTI, 1985; PIE y RIBE, 1991; RUBí, 1995; PARDO, 1996, y ROMÁN, 1996).

\section{LOS PRIMEROS PASOS EN LA INVESTIGACIÓN DEL NEOLFICO PENINSULAR}

Las investigaciones sobre el Neolítico peninsular están marcadas como es natural por la marcha de la investigación prehistórica en general dentro y fuera de la Península. 
El siglo XiX, momento del nacimiento de la Prehistoria como disciplina independiente, cuenta en España con ilustres investigadores que, al igual que sucede más allá de nuestras fronteras, proceden en la mayor parte de las ocasiones de otros campos del saber distintos al histórico. Otra particularidad de la investigación prehistórica española es la presencia de estudiosos extranjeros. Determinados hallazgos proporcionarán asimismo la ocasión de poner en marcha una determinada línea de actuación o servirán para despertar el interés por una etapa concreta. La polémica evolucionista permitió a muchos de los estudiosos españoles participar en un debate cientifico de primer orden. ligándose así la investigación en un primer momento y para las etapas más antiguas de la vida del hombre a las Ciencias Naturales. Este enfoque contará igualmente con representantes en la primera mitad de nuestro siglo.

Desde una perspectiva global conviene tener en cuenta las circunstancias y el contexto en que se inician las investigaciones del Neolítico peninsular. Recordemos, por lo que se refiere a Europa, que ya en $1840 \mathrm{~W}$. Wilde habia elaborado un informe sobre los descubrimientos de los pantanos irlandeses, que en la década de los cincuenta del siglo pasado F. Keller lo habia hecho sobre los poblados lacustres suizos y en 1890, Munro había ofrecidio una sintesis de todos los conocidos en Europa en esos años. Tal como ya se ha señalado, no todos ellos son neolíticos, pero de rechazo constituyen los primeros estudios de algunos grupos europeos pertenecientes a ese momento. Al mismo tiempo, en las primeras sistematizaciones de la Prehistoria se insinúa tímidamente una etapa caracterizada por un nuevo modo de trabajar la piedra. No será tanto en el Sistema de las Tres Edades elaborado por C. J Thomsen en 1836 y afianzado por J. J. A. Worsaae después de las excavaciones de los túmulos de Jutlandia, cuanto en las subdivisiones introducidas en 1865 por J. Lubbock donde aparecerá ya el término Neolitico para designar una nueva etapa cultural dentro de un contínuo evolutivo.

Es evidente que el pulimento de piedras duras se inicia de forma generalizada en el Neolítico continuando después, por lo que la indefinición de los restantes aspectos que caracterizan a este momento propició la confusión del mismo con el del primer conocimiento de la metalurgia presente en las primeras investigaciones peninsulares, resultando explicable desde estos planteamientos. No obstante. prácticamente al tiempo se reconoce como otra "novedad" neolítica la cerámica, pasando a caracterizar ambas innovaciones tecnológicas los hallazgos supuestamente neolíticos.

Sin embargo, investigadores de otros campos utilizan ya entonces criterios diferentes para sistematizar las sucesivas etapas de la vida de la Humanidad. Así, S. Nilsson, catedrático de Zoología, formula en 1834 una secuencia basada en los modos de subsistencia. En este mismo siglo, es de sobra conocida la elaborada por el antropólogo americano L. Morgan en 1877, adoptada posteriormente por autores marxistas. Dichas categorias en que dividen la Historia del hombre son herencia de las establecidas por el pensamiento ilustrado, que hallamos en Turgot, Montesquieu o en la misma Enciclopedia. En ellas, los estadios económicos resultaban intercambiables con los sociales, dentro siempre de unos parámetros evolucionistas. 
En otro orden de cosas, A. de Candolle inicia en 1884 el primer intento serio de investigación del origen de las plantas cultivadas. H.L. Roth continúa esta línea de trabajo en 1887 con un planteamiento multidisciplinar (Botánica, Historia y Filologia), dando paso a la idea de la existencia de centros originarios de las plantas posteriormente cultivadas (WRIGTH, 1971, 112.113)

Sin embargo, durante el siglo XiX la investigación en el Próximo Oriente continuó centrada en las antiguas civilizaciones, siendo prácticamente inexistente la de los momèntos prehistóricos, criterio que se mantendrá hasta bien entrado el s. XX. Sin embargo. pó las mismas causas se genera la consideración de este área como foco civilizadior para el continente europeo fundalmentalmente.

La primera obra relacionada con un yacimiento supuestamente neolítico que encontramos en la bibliografía peninsular es la publicada en 1868 por el catedrático de Granada, D. Manuel de Góngora: Antigüedades prehistóricas en Andalucía. Con la terminologia propia del momento, da a conocer los materiales de la Cueva de los Murciélagos de Albuñol, proporcionando también su representación. Él mismo levanta el plano de la cueva, recoge materiales in situ así como otros dispersos obtenidos durante los trabajos de explotación del salitre. Sin embargo, la actuación de Góngora no estuvo exenta de posterior polémica e incluso de censura, probablemente injusta. Las circunstancias que contribuyeron a la progresiva destrucción del yacimiento y en las que se obtuvieron los materiales suscitaron dudas sobre su autenticidad en un momento dado (GOMEZ MORENO, 1933) Esto hizo que hasta los años setenta no se revisaran los materiales y se obtuvieran fechas de C14. En la valoración que $M$. de Góngora hace de los materiales, se pone de manifiesto la consulta de la obra de J. Lubbock al que cita en traducción francesa, cuando defiende el conocimiento del oro anterior al de otros metales, aportando como paralelos pueblos más recientes como los fenicios (GONGORA, 1868, 53) El manejo de esta obra podría considerarse como una prueba de la amplia y rápida difusión de la misma, de la puesta al día de la erudición de Góngora o de ambas cosas.

No mucho tiempo después se uniráa a ésta la publicación de la Cueva de la Mujer, también neolítica, por McPherson en 1870.

Estas mismas fechas son las de los inicios de la investigación prehistórica dentro y fuera de nuestras fronteras (recordemos el descubrimiento de Altamira en 1868 y trabajos como los de Casiano del Prado o Vilanova y Piera).

A finales de siglo, el ingeniero L. Siret, contratado junto con su hermano Henri por la Compañia Minera de la Sierra Almagrera, había establecido ya una primera sistematización del Neolítico peninsular (1892). El Neolítico antiguo, industrialmente hablando, se situaba en pleno Paleolítico, produciéndose en el Neolítico medio el primer conocimiento de la metalurgia (Los Murciélagos) e incorporándose nuevos elementos en el reciente. Posteriormente (1893), estas etapas se verán reducidas a dos, identificándose siempre el Neolitico con el momento de primer uso del metal. Para L. Siret, la afinidad de los testimonios peninsulares considerados neolíticos con Troya resultaba evidente, destacando por esa misma razón, la importancia de las relaciones marítimas. Se hallaba inmersa su explicación en el contexto difusionista más al uso, lo mismo que la determi- 
nación del punto de partida: Troya, yacimiento suficientemente conocido a la sazón a través de los trabajos de H. Schliemann y de W. Dörpfeld.

\section{LA OBTENCIÓN DE LOS DATOS Y LA FORMULACIÓN DE LAS PRIMERAS TEORÍAS}

Al igual que sucede en los restantes paises europeos (la investigación prehistórica se podia considerar hasta hace poco tiempo fundamentalmente eurocéntrica con el correspondiente sesgo en las interpretaciones), la primera mitad del s. XX se ocupa de la recogida de datos, aplicando la reciente excavación sistemática aunque desgraciadamente no siempre; de la clasificación de los restos materiales con arreglo a un fósil-director y a su integración en tipologias, además de la elaboración de un marco cronológico relativo, bajo el influjo del difusionismo y el particularismo en la investigación, como ya es sabido.

N. I. Vavilov continúa los estudios de A. de Candolle en la investigación paleobotánica, prolongándose los suyos desde finales del s. XIX y durante la primera mitad del s. XX. Tales estudios permitirän adentrarse en el conocimiento de las primeras especies cultivadas y de su historia, introduciendo otros criterios para el estudio de los grupos neolíticos. Será el investigador ruso el que establecerá las zonas de hábitat natural de las plantas. Otros paleobotánicos desarrollarán sus trabajos en fechas similares, como en el caso de E. Schiemann en 1932 y A. E. Watkins en 1933 (WRIGTH, 1971, 117)

Esta circunstancia generará un nuevo debate acerca de la primacía de la agricultura sobre la domesticación de animales y viceversa, debate pendiente en todo caso desde el s. XVIII y que, considerado de forma absoluta, no se plantea hoy como el centro de interés para ningún prehistoriador

En España, la investigación del pasado se institucionaliza de algún modo a través de la creación de los organismos pertinentes y de la promulgación de leyes que regulan estas actividades, así como de la creación de las primeras cátedras. Sin embargo, los investigadores seguirán teniendo variadas procedencias, al menos en un primer momento.

La creación en 1907 de la Junta para la Ampliación de Estudios e Investigaciones Científicas supone la posibilidad de que algunos arqueólogos puedan viajar al extranjero, con preferencia a Italia y Alemania. El acercamiento sobre todo a este último país supone la introducción del método histórico-cultural y la planificación del trabajo de campo en Prehistoria y poco a poco en la Arqueología clásica. Los planteamientos señalados al principio, en vigor en las escuelas de raíz germana desde los últimos años del siglo anterior, van a ejercer una influencia decisiva en determinados investigadores dedicados a la Arqueología prehistórica, como es visible en la utilización de "círculo cultural" como concepto historiográfico (P. Bosch Gimpera, L. Pericot o A. del Castillo). Otros investigadores como J. Martinez Santa Olalla o M. Almagro Basch pasan igualmente por Alemania. Como señalan M. Díaz Andréu y G. Mora (1995), si tenemos en cuenta que todos ellos ocuparon cátedras y cargos destacados relacionados con la Arqueología española. queda 
clara la repercusión de las teorias mencionadas en los trabajos realizados por ellos y sus discipulos.

En todo caso, lentamente, desde los inicios de este siglo, se va configurando el Neolítico peninsular como una etapa con diversos horizontes caracterizados por la aparición de sucesivas innovaciones, procedentes o no del Próximo Oriente a través de vías de llegada más o menos claras (RUBiO, 1995).

En 1925, J. Colominas publica su Prehistoria de Montserrat, identificando por primera vez la cerámica que hoy conocemos como impresa cardial y que constituye el fósildirector del Neolítico más antiguo de la mitad occidental del Mediterráneo. El término montserratina que entonces se le aplicó fue desechado posteriormente al quedar patente la amplia difusión de esta especie cerámica.

Durante los años veinte y treinta, autores como P. Bosch Gimpera proponen una serie de periodos para el Neolítico peninsular o bien círculos o culturas que pueden ser o no sucesivos. Se evidencia aqui la influencia antes citada de la escuela alemana. Así. cabría destacar la distinción de la denominada cultura de las cuevas con rasgos culturales precisos, distintos en cualquier caso de los que caracterizan a la que con el mismo nombre designaron algunos autores posteriormente para la zona andaluza (NAVARRETE. 1976, y ARRIBAS y MOLINA, 1979), sin demasiada justificación en mi opinión. En segundo lugar, puede citarse la definición de cultura de Almeria (BOSCH GIMPERA, 1932), de la que se hará más tarde un estudio pormenorizado (BOSCH GIMPERA, 1969), comúnmente considerada entonces como el origen de la catalana de los sepulcros de fosa y la delimitación de las culturas pirenaica y megalítica portuguesa (ROMÁN, 1996, 62-78).

Cabria destacar en estas obras como en las de otros contemporáneos (PERICOT, 1934). la importancia otorgada a las relaciones con el norte de Africa y Egipto como foco originario que aparece recurrentemente en otros escritos posteriores (BOSCH GiMPERA, 1965), al defender la existencia de un Neolítico circummediterráneo con variantes regionales.

Estos planteamientos: la cronologia tardía del Neolítico peninsular coincidente con la metalurgia, la delimitación de varios círculos culturales y la extensión hacia el norte de la cultura de Almeria se verán plasmadas en la obra de L. Pericot ya citada (1934), en posteriores reediciones de la misma (Pericot, 1950) o en otras (PERICOT, 1967) en las que sin embargo, se acepta la posibilidad de un camino europeo de llegada para las innovaciones neolíticas.

Conviene recordar que en los años treinta se tuvieron las primeras noticias sobre la Cova de l'Or (Alicante) a través de los trabajos de D. Rafael Pardo en 1934 y 1935, que continuaron en los inicios de la década siguiente. De igual manera, J. San Valero publicaría en 1942 los primeros materiales procedentes de la Cueva de la Sarsa (Valencia), que completaría con otros en el año 1945. Los restos proporcionados por ambos yacimientos no pudieron por menos que llamar la atención sobre la riqueza del registro arqueológico de este momento de la Prehistoria peninsular, especialmente en la fachada mediterránea.

Por otra parte, la publicación de una primera fase de las excavaciones de Arene Candide por L. Bernabó Brea en 1946 (un segundo volumen aparecerá en 1956) (BERNA- 
BO BREA, 1946 y 1956), supuso un hito importante para los investigadores del Neolítico mediterráneo. El autor italiano situaba el origen de éste en el Próximo Oriente desde donde se habria difundido por vía marítima, lo que representaba también los inicios de la navegación en este área. El V. milenio parecía una cronología adecuada para el Neolítico antiguo de cerámica impresa del Mediterráneo occidental, ya que esta difusión habria sido bastante rápida. Si en un principio Bernabó Brea aceptaba la dispersión por el norte de Affrica, en 1956 descarta esta vía para ratificarse en la maritima, por la que la neolitización llega a las costas de ambas márgenes del Mediterráneo central y occidental y desde donde se expandirá hacia el interior.

Durante la década de los cuarenta se impone la división tripartita del Neolítico propuesta por J. Martínez Santa Olalla (1946b) que se verá reflejada en las obras de otros autores (SAN VALERO, 1946; PERICOT, 1950; ALMAGRO BASCH, 1970, etc.), reducida a dos horizontes. El Neolítico antiguo, identificado con el Mesolítico se verá sucedido por uno reciente, dividido a su vez en dos momentos sucesivos: el hispano-mauritano y el ibero-sahariano, originarios del Próximo Oriente y Egipto respectivamente. A este mismo autor se debe la primera publicación sobre cereales prehistóricos procedentes de Almizaraque (MARTínEZ SANTA OLALLA, 1946a), en la que se defiende la necesidad de estudios económicos y sociales frente a los puramente tipológicos. Supone este artículo la primera aportación de esta índole a la literatura científica sobre la Prehistoria y no cabe duda de que contribuyó a abrir una nueva vía que, si en cualquier caso es importante, doblemente habría de serlo en la investigación sobre el Neolítico. Desgraciadamente, hasta bastantes años más tarde no cundirá el ejemplo sugerido por el mismo.

J. San Valero proporciona un nuevo impulso a los estudios sobre el Neolitico peninsular, partiendo de presupuestos igualmente difusionistas y siguiendo el esquema establecido por Martínez Santa Olalla. Como curiosidad puede citarse en alguna de sus publicaciones (SAN VALERO, 1946) un intento de estudio sobre posibilidades de navegación que autores posteriores trataron de lievar a cabo también y que está directamente relacionado con la supuesta llegada de gentes y de "novedades" a partir del Próximo Oriente.

Me gustaría resaltar que, paralelamente, F. Jordá y J. Alcacer (i948), en la publicación de la Cueva de Llatas (Valencia), señalan la existencia de un Neolítico inicial de montaña documentado también en la Cueva de la Cocina (Valencia), caracterizado entre otras cosas por las cerámicas lisas. Conviene señalar que, aparte de enlazar con lo expuesto dos años después por San Valero y unido a lo que se creyó detectar en otros yacimientos, este hecho generó la defensa por parte de algunos autores de la existencia de un Neolítico de cerámicas lisas anterior al de la cerámica impresa cardial no confirmado posteriormente.

J. San Valero haria notar la presencia en el área levantina de un Neolítico marginal de montaña con ocasión de la publicación definitiva de la Cueva de la Sarsa (1950), Neolítico que sería asimismo inicial para estas gentes. Podriamos sin duda situar aquí el origen del modelo dual supuestamente perceptible en la franja mediterránea que ha llevado a autores más recientes a la defensa de una explicación en el mismo sentido para el Neolitico valenciano y de rechazo para el peninsular. 
A través de las precisiones publicadas por los diversos autores sobre cuestiones que empiezan a objetivarse en el registro arqueológico se inicia, de algún modo, la ruptura de la rigidez impuesta por las secuencias existentes y la consideración de la variabilidad que traduce lo complejo de la neolitización.

A. del Castillo opina sin embargo en 1947 (1963), que el Neolitico puro no existe en ninguna de las áreas peninsulares y lo aborda como un bloque, distinguiendo tres circulos culturales distintos: la cultura de las cuevas, la megalítica y la de Almería con elementos norteafricanos, egipcios e incluso egeos. En la denominación misma se pone de manifiesto la escasa definición que tiene para este autor Neoeneolitico, término que nọ será empleado por él sólo.

Las peculiaridades del Neolitico andaluz y su acusada personalidad con respecto a otros focos peninsulares se pusieron pronto de manifiesto reforzando la creciente impreșion de complejidad del Neolítico peninsular. J. Martínez Santa Olalla se ocupó en su momento (1948), de la cronología de la cerámica a la almagra, característica de esta zona, situándola en el Neolítico pleno o reciente y defendiendo su origen en el Creciente Fértil desde donde se habria difundido hacia el Egeo y el Mediterráneo occidental. Posteriormente, Gómez Moreno (1949) compartiría similares criterios cronológicos, relacionándola con el Próximo Oriente y Chipre.

Es necesario tener en cuenta que durante la primera mitad de nuestro sigio y desde la formación de la Teoria clásica a partir de las publicaciones de V.G. Childe en los años treinta (VICENT, 1988), en las que se exponía la después denominada Hipótesis del oasis y su interpretación de la Revolución Neolítica, ésta sustituirá a otras ya existentes (la de los valles de los grandes rios, fundamentalmente) y será habitual como explicación. En general en una primera etapa, como señala A. Hernando (1994), se busca sobre todo el lugar donde se opera este cambio. Así, Gordon Childe afirmaba en 1936. que el cambio se produjo en el Próximo Oriente por causas medioambientales, pero no sólo: "... apenas terminada la Edad del Hielo, la actitud del hombre (o més bien de algunas comunidades) hacia su medio ambiente sufrirá un cambio radical, preñado de consecuencias para la especie entera" (CHILDE, 1972, 85-130). Un aspecto subsidiario, pero de gran importancia para nosotros, es la observación de que con el agotamiento de la tierra se produce el traslado a otras áreas para practicar la agricultura de azada. En otras palabras, se puede señalar aquí la plasmación de la idea de una supuesta colonización neolítica de Europa por parte de los primeros agricultores próximo-orientales.

No será hasta los años posteriores a la II. ${ }^{a}$ Guerra Mundial cuando se detectarán en el Próximo Oriente y después en el Egeo la existencia de grupos precerámicos que llevarán a una variación conceptual del Neolítico. A partir de ese momento, la producción de alimentos, considerada igualmente como una innovación, será el rasgo determinante de la nueva etapa cultural y cronológica. La especulación sobre el orígen de las primeras especies domésticas reforzará en todo caso los planteamientos difusionistas. Los citados descubrimientos conducirán a la aceleración de excavaciones que tendrán por objeto el estudio de horizontes prehistóricos y al inicio de la aplicación de la datación radiocarbónica en las respectivas áreas. Todo ello, si tendra eco en la investigación 
peninsular, aunque el cambio en los planteamientos se opere lentamente. En todo caso, la importancia de los procedimientos analíticos tomados de otros campos de la Ciencia sera determinante en este sentido en los estudios posteriores.

A finales de los años cuarenta, se reabre el debate sobre los inicios de la agricultura, tratando de comprobar si los cambios medioambientales de los comienzos del Holoceno constituyen el detonante de este proceso. Recordemos que se inicia el Proyecto Irak-jarmo (en 1948 y hasta 1955), dirigido por R. Braidwood y B. Howe. Puesto que no consiguen documentarse los cambios antes aludidos, la discusión vuelve a centrarse en el punto de origen, siempre dentro del Próximo Oriente (altiplanos, zonas de piedemonte superior y valles intermontanos para Braidwood. Harlan y Zohary; bosques subtropicales de tipo Mediterráneo para Butzer o de pradera para Van Liere y Contenson).

En los años cincuenta la actividad en las distintas regiones peninsulares se amplía. En el vecino país, F. Rusell Cortez publica un artículo (1953) en el que indica cómo sobre los concheros mesolíticos llegaron las gentes neoliticas en su expansión, produciéndose una integración que dará como resultado dos culturas entre el Tajo y el Duero: una agricola y otra pastoril que será producto de los constructores de megalitos. Este esquema dual que no puede hoy ser tomado en cuenta, puso ya entonces de relieve la larga perduración de los concheros, así como lo temprano del megalitismo, estando confirmadas en la actualidad ambas cosas.

D. Fletcher (1956) por su parte, detectaba una doble faceta (triple en realidad) en el entonces denominado Neolítico hispano-mauritano: cerámica cardial sin industrias geométricas en la costa que, en cambio, si aparecian en el interior junto con cerámicas incisas y sin cardial. En una zona intermedia, Or y Sarsa ofrecían cerámicas cardiales además de los geométricos citados. Se trata de un paso más en la configuración del modelo dual posterior.

Durante los primeros años cincuenta las recogidas de material en la Cova de l'Or, efectuadas por V Pascual, llevarian a sucesivas campañas de excavación a partir de 1955 y hasta finales de la década, dándose noticia de las mismas en 1961 (Plá).

En el año 1959, uno de los ya por esas fechas escasos representantes de la corriente de investigación prehistórica ligada a las Ciencias Naturales, E. Hernández-Pacheco, plantea aspectos relativos a la domesticación de las primeras especies y al origen de algunas variedades, con una visión de auténtica modemidad para el momento y que, inexplicablemente, no se han resaltadio en la bibliografia existente sobre esta temática, independientemente de que el tiempo se haya encargado de superarlos. Por lo que respecta a otras cuestiones, señala: "El neolítico deriva directamente del mesolítico mediante evolución autóctona..." (1959, 534). Sin embargo, en su opinión, algunas especies llegan domesticadas del exterior (HERNANDEZ-PACHECO, 1959, 535 y 539).

La celebración del I Symposium de Prehistoria Peninsular en ese mismo año permite a los distintos autores la revisión de conceptos y la sintesis de problemas relativos al Neolítico. Bosch Gimpera (1961) por ejemplo, admitirá para los sepulcros de fosa relaciones con las culturas occidentales de Chassey-Lagozza. Durante mucho tiempo, 
como veremos, fue práctica corriente la inclusión de la citada cultura catalana en el círculo occidental europeo caracterizado por cerámicas lisas (TARRADELL, 1963). Recientemente, A. M. ${ }^{a}$ Muñoz $(1997,267)$ ha recordado ciertas semejanzas con dichas culturas europeas al defender una cronología del Neolitico reciente para los sepulcros de fosa. frente a otras opiniones que los sitúan en la fase media del Neolítico catalán.

M. Tarradell (1959) rechaza categóricamente la relación de origen de esta misma cultura con la de Almeria. Será este investigador quien igualmente deseche el término montserratina para la cerámica cardial, proponiendo en su lugar el de cerámica impresa a causa de la variedad decorativa observada. De la misma manera, dejará de admitir el término Neo-eneolítico, puesto que, en su opinión, era perfectamente posible diferenciar ambas fases, reemplazando el término Bronce I (propuesto por el I C.A.N. celebrado en 1949 para designar la etapa inicial de los metales), por el de Eneolítico.

Con estos autores se cumple una etapa de la investigación presidida por una concepción difusionista de la neolitización que supone la llegada de colonos foráneos y una valoración importante del Próxirno Oriente, Egipto y en menor medida el Egeo como focos originarios. Este paradigma explicativo Ileva, como consecuencia inmediata, a la especulación sobre posibles vias de llegada: marítima o terrestre, optándose en este segundo caso por la norteafricana o defendiendo, de algún modo, las relaciones con éste área, como se desprende incluso de los términos empleados para designar ciertas culturas (recordemos la sistematización de Martínez Santa Olalla, por ejemplo). Así, Bosch Gimpera (1974, 61-62 y 68) hace descender a las poblaciones neo-eneolíticas de las "infiltraciones capsienses de finales del Paleolítico superior y del Mesolítico ${ }^{n}$, representando, más tarde, la cultura de Almeria "nuevas infiltraciones africanas, relacionadas con la cultura sahariense"

Tal camino está absolutamente desechado en el momento actual, pero no estrictamente el contacto con el área magrebi (margen norteafricana del Estrecho de Gibraltar), para el que se ha sugerido una dirección Península-norte de Africa visible en las escasas cerámicas cardiales de los yacimientos costeros marroquíes (CAMPS, 1984) Seguramente, este énfasis en las relaciones con el Magreb no es ajeno a la presencia española en la zona y al desarrollo en la misma de una importante y eficiente labor arqueológica (FERNANDEZ, 1996, 241-256).

La ausencia o parquedad de datos sobre el Epipaleolítico de cada área justifica la confusión, en múltiples ocasiones, de éste con la etapa más antigua del Neolítico. Dada la falta de dataciones absolutas, las cronologias atribuidas por los distintos autores suelen ser bajas, identificándose todo el Neolítico o el horizonte más avanzado, sobre todo en las obras más antiguas con el primer conocimiento del metal.

Por otro lado, durante los primeros años de este siglo se había producido ya el estudio de los yacimientos centroeuropeos del Neolítico denominado danubiano, se habia iniciado el de algunos tells de los Balcanes y se trabajaba asimismo en los importantes yacimientos tesalios de Sesklo y Dímini. Igualmente se conocían numerosos monumentos megalíticos de la Europa occidental. 


\section{LA PRIMERAS APLICACIONES DEL MARCO AUXILIAR AL ESTUDIO DEL NEOLITICO PENINSULAR}

El desarrollo de la Teoría Clásica durante los años sesenta (VICENT, 1988, 28-40) modifica escasamente lo relativo a la explicación de la neolitización europea en general y peninsular en particular, razón por la cual no se plantean otras posibilidades en este sentido. Este desarrolio se había producido a través de la formulación de nuevas teorias explicativas de la neolitización. R. Braidwood y G. Willey (1962) habían determinado ya en 1962 la multiplicidad de focos originarios, considerando la cuestión a escala mundial y para distintas especies animales y vegetales (Teoria de las áreas nucleares), explicando el primero de estos autores (BRAiDWOOD, 1960, 134) la aparición de la agricultura por una especialización de distintas comunidades humanas entre otras causas.

Según A. Hernando (1994, 128 y ss.), a partir de la expansión de la "Nueva Arqueología" en los años sesenta se produce la reformulación de los postulados del determinismo ambiental clásico. En su opinión, una de las direcciones tomadas, lleva en términos más o menos materialistas, a la Escuela Paleoeconómica de Cambridge y a su "British Academy Major Research Project on the Early History of Agriculture", desarrollado entre 1968 y 1976. dirigido por E. S. Higgs y M. R. Jarman y otra, en términos evolucionistas, bajo la estructura de la Teoria de Sistemas al Proyecto Oaxaca de Flannery (puesto en práctica desde 1966 a 1973 y en unión de J. Marcus desde 1974 a 1981). Sobre la primera volveremos inmediatamente después; el resultado de la segunda fue un estudio excelente desde la prospección inicial hasta las conclusiones, con especial énfasis en la organización social y el mundo simbólico.

Pero nos interesa aquí otra aportación del investigador norteamericano como es la formulación de la posteriormente denominada Teoría de las áreas marginales en 1969. Implica esta teoría una "revolución" previa (la de amplio espectro con relación a los recursos explotados); ciertas mutaciones en las especies silvestres y un desequilibrio en la densidad de las poblaciones humanas. Se valora por primera vez al igual que en la escuela inglesa el proceso biológico de la domesticación, aunque desde planteamientos diferentes.

Desde ámbitos distintos de la investigación. Harlan y Zohary, profesores de Agronomía y de Botánica respectivamente, señalarán la distribución actual de trigos y ceba* das, experimentando incluso el primero de ellos y recolectando Triticum boeoticum con hoces de sílex. H. Helbaek investigará tambièn entre 1966 y 1969 sobre el proceso que dará paso a las especies domésticas (WRIGTH, 1971, 123-124).

La elaboración de teorías sobre el Neolítico peninsular, su origen, periodización y relaciones avanza sobre las bases que se han ido cimentando gracias a la labor de los investigadores citados. Se plantean ahora nuevas posibilidades en todo los sentidos a causa de la aplicación de nuevos métodos provenientes en muchos casos de otros campos de la ciencia, agotadas ya por otra parte, algunas de las vías señaladas o necesitadas otras de un impulso renovador. Sin embargo, la explicación de la neolitización peninsu- 
lar se mantiene en términos similares a los expuestos, trabajándose sobre todo en perfilar los diversos horizontes con carácter más o menos regional, siempre con la mirada puesta en el este del Mediterráneo. Las investigaciones varían escasamente en sus planteamientos interpretativos, pero como contrapartida se perfilan con mayor precisión los horizontes constatados en las regiones mejor estudiadas.

La propuesta en 1961 por parte de A. Arribas de otra sistematización del Neolítico. en la que se introduce como novedad la posible existencia de uno meridional más tardío que el de las cerámicas impresas y anterior a los sepulcros de fosa, supone la primera valoración independiente del Neolítico andaluz y una contribución más a los esfuerzos por matizar convenientemente los componentes de este proceso/etapa cultural y cronológica.

En el mismo sentido, M. Tarradell (1963) introduce nuevos matices planteando la duda sobre los supuestos Neolíticos iniciales de Cocina y Llatas y sugiriendo su consideración exclusivamente como un fenomeno marginal arcaizante.

La publicación por parte de M. Pellicer de las excavaciones de las Cuevas de Nerja (Málaga) (1962) y Carigüela (Granada) (1964) respectivamente, resultó trascendental para el estudio del Neolítico andaluz, ya que constituyen aún algunos de los escasos ejemplos dotados de estratigrafia en este área. Los numerosos problemas suscitados por las cuevas andaluzas eran puestos de manifiesto también por $M$. Tarradell (1964), señalando como el principal de ellos la carencia de estratigrafías y manteniendo una cronología eneolítica para la cerámica a la almagra. Evidentemente, la anterior constatación de la perduración de esta especie cerámica en yacimientos con enterramiento colectivo (NiETO, 1959), favorecía sin duda esta impresión.

A. M. ${ }^{a}$ Muñoz publicaba en 1965 lo que seră el corpus de referencia de la cultura de los sepulcros de fosa. En esta obra de conjunto quedaban definidas las caracteristicas de su cultura material y su carácter agrícola. estableciéndose la distinción con los grupos que practicaban el enterramiento colectivo. Para la autora se trataba de una segunda oleada de colonos provenientes del Mediterráneo occidental. Es interesante recordar cómo M. Maluquer, en el prólogo a dicha publicación, sugería la posibilidad, no demostrada después, de "un periodo acerámico" para la Península Ibérica.

Las primeras dataciones absolutas para un yacimiento neolítico peninsular, la Cova de l'Or, ven la luz igualmente en esos momentos (SCHUBART y PASCUAL, 1966), permitiendo situar sus materiales cardiales en el $\mathrm{V}^{\circ}$ milenio. dándose la feliz circunstancia de que dicha datación se producirá a partir de los hallazgos de cereales de esta cueva que asimismo fueron publicados en el mismo año (HOPF y SCHUBART, 1966). La importancia de las mismas ha sido ya valorada anteriormente por mi parte (RUBIO, 1995)

Las investigaciones en Portugal, por lo que a estudios sobre el Neolítico se refiere, permanecian en cambio un tanto frenadas, aunque en $1967 \mathrm{~V}$. Leisner sistematizara lo que se conocía del mismo. 
M. Pellicer (1967) plantea en ese mismo año una visión del Neolítico diferente de las elaboradas en aquel momento, volviendo de nuevo a la distinción de hasta siete círculos culturales en la Península cuya evolución estudia de forma especifica.

La contribución más destacada de esos momentos con respecto a nuevos planteamientos junto con los datos procedentes de la Cova de l'Or, se debe a A. Arribas (1968), con un articulo que constituye el primer trabajo de síntesis sobre los aspectos económicos del Neolitico y el Bronce peninsulares. El indice de los temas tratados resulta enormemente ilustrativo sobre la indole del mismo pero también sobre la escasez de datos existentes, lo que se refleja en la inclusión de ambos periodos en el mismo estudio. Supone un cambio en la visión de la cuestión neolítica, pero también y sobre todo la apertura de un camino nuevo para trabajos de investigación posteriores.

\section{EL NUEVO RUMBO MARCADO POR EL INTERES POR LOS ASPECTOS ECONOMICOS EN LAS INVESTIGACIONES DEL NEOLÍTICO PENINSULAR}

La década de los setenta se inicia ya, a mi juicio, desde otras perspectivas. A. M. ${ }^{a}$ Muñoz (1970) expone en un artículo que tendrá su continuidad en otros dos posteriores. el estado de la investigación partiendo del nuevo concepto de Neolítico considerado como un cambio en la economía pero manteniendo las posiciones difusionistas que llevan a buscar el origen en el Próximo Oriente.

Recordemos que durante esos años se están ofreciendo otras hipótesis de trabajo en el estudio del Neolítico europeo como son las planteadas por la Escuela de Cambridge. En un artículo publicado en 1972, Hiiggs y Jarman consideran que la domesticación de plantas y animales es el resultado de un conjunto de desarrollos naturales de procesos comunes en patrones de explotación humanos y no humanos más que de una serie de invenciones del Postglaciar (HIGGS y JARMAN, 1972, 12). Por esta razón, la buisqueda de los orígenes de la misma no debe seguirse relacionando exclusivamente con lo que ha sido en el pasado. En cuanto a Europa, aunque los antecesores de ciertas especies se hallen en el Mediterráneo oriental (con reservas), creen poco probable que las técnicas se hubieran introducido en una Europa completamente explotada por economías de caza y recolección. Es asimismo poco probable que en las épocas glaciares y postglaciares el aprovechamiento de los recursos hubiera sido tan uniforme. En su opinión, las economias del Tardiglaciar tuvieron que ver más con el pastoreo o control del reno que con una caza ecléctica practicada al azar. La investigación sobre las plantas, a su vez, se había dirigido únicamente a la detección de los cambios morfológicos cuya ausencia no es suficiente para demostrar que no se produjo el cultivo. Por todo ello, consideraban que el estudio de los territorios de los yacimientos y la utilización del terreno tenía bastante que aportar en este sentido (HIGGS y JARMAN, 1972, 13).

Los planteamientos fundamentales del Proyecto citado en páginas anteriores eran tres en opinión de G. Barker $(1985,8-9)$ : la posibilidad de una agricultura antigua post- 
glaciar en el Viejo Mundo fuera de la zona originaria como permitían pensar los testimonios zoológicos y botánicos; la continuidad de un proceso desde los inicios del Postglaciar hästa hoy (según las fechas de domesticación de animales y plantas) y la necesidad de buscar los origenes de la agricultura más atrás en el tiempo, si se consideraba que la domësticación era un cierto proceso de selección natural de la población humana y no el resultado de un oportunismo cultural.

En otras palabras, se cuestionaba la explicación difusionista valorando en cambio los procesos autóctonos. En esta dirección se orientó la investigación posterior de dicha Escuela (HIGGS, Ed., 1975 y JARMAN, BalleY y JARMAN, 1982), relacionando el Neolítico antiguo europeo de economia agricola mixta con un considerable incremento de la población, siempre en el marco de los parámetros antes señalados (JARMAN, BALLEY y JARMAN, 1982, 71).

A pesar de que en opinión de Ruiz Zapatero $(1988,81)$, esta aproximación no constituye una corriente teórica general, sino una metodología de trabajo con un conjunto de instrumentos analíticos que permiten un acercamiento a sistemas paleoeconómicos, a mi modo de ver, de las dos corrientes señaladas por A. Hernando la representada por Flannery no tuvo en modo alguno la misma repercusión en nuestro país que la que acabamos de comentar a pesar de la calidad de la investigación realizada, ya que además hasta 1983 y 1986 no se dieron a conocer los resultados de manera completa. Las publicaciones y los planteamientos relacionados más o menos directamente de la "Nueva Arqueología" no fueron conocidos de forma generalizada en esos momentos 0 , si lo fueron, no tuvieron su reflejo en las investigaciones peninsulares hasta bastantes años después. $Y$ desde luego, no generaron entonces ningún tipo de teoria explicativa sobre el Neolítico peninsular. En cambio, al menos los procedimientos analíticos derivados de la Escuela Paleoeconómica o Paleoambiental de Cambridge, sí lo fueron aunque su aplicación efectiva y de forma más amplia fuera también más tardia.

Del mismo modo que J. D. G. Clark (1952), fundador de la citada Escuela, experimenta el influjo del funcionalismo los seguidores de esta aproximación no permanecen ajenos a las orientaciones que aparecen en la comunidad investigadora. A ese respecto $\checkmark \mathrm{V}$ A. Shnirelam (1994.40) destaca que es justamente este autor el primero que insiste en la continuidad entre cazadores-recolectores y neolíticos en términos de tecnología y economia. La necesidad de abordar el estudio del Neolítico europeo desde otros planteamientos, habida cuenta del callejón sin salida en el que éste parecía haber entrado, se refleja en las obras de dichos autores. En ese sentido, se evidencia un enfoque de punto de partida que aunque pueda no constituir una teoría antropologica general, imprime un giro a las investigaciones del que, sobre todo las peninsulares, estaban necesitadas para salir de un cierto estancamiento en el debate. La diferencia con orientaciones como las provenientes de las escuelas norteamericanas antes citadas se halla en el punto de partída: restos materiales (normativismo) o modelos de carácter antropológico (paradigma hipotético-deductivo). La opción no se planteaba así, de todos modos, en ese momento en la investigación peninsular. 
La interrupción de las explicaciones de corte evolucionista: aparición de la agricultura como un estadio superior dentro de una progresión que constituye la historia del hombre, motivada por la nueva visión sobre los cazadores-recolectores que plantea la publicación por Lee y De Vore en 1968 del simposio Man the hunter, comenzaba a ser un hecho fuera de nuestras fronteras.

En este contexto se enmarcan las denominadas Teorias de desquilibrio que inciden en el modo de conseguir nuevos tipos de alimento y más cantidades en relación con el aumento de la población ' la domesticación es un modo de enfrentarse a periodos de escasez. Asi, cabe citar la formulada por L.R. Binford (1968) quien consideraba la cultura como un sistema adaptativo por lo que se genera una cierta capacidad de predicción (la ocupación de nichos ecológicos similares permitiría esperar innovaciones paralelas independientes).

Desde una perspectiva enmarcada en el Materialismo histórico (HERNANDo, 1994, 131). B. Bender (1978) señalaba que son los factores de transformación social interior los que deben ser analizados. Su explicación radica en que las relaciones de alianza son fundamentales para garantizar la supervivencia de los grupos de cazadores-recolectores. Ello implica reciprocidad, es decir, intercambio de bienes que, si no es inmediato, da paso al aimacenamiento. Éste potencia el sedentarismo, el cual propicia a su vez la presión social y ésta un liderazgo que interviene en el control de acceso a los recursos.

A mi modo de ver, sin embargo, ambas aproximaciones, la paleoambiental o paleoeconómica inglesa y la antropológica norteamericana ponian de relieve, desde puntos de vista diferentes, una necesidad evidente: la de retrotraer la investigación del origen de la producción de alimentos o al menos de la domesticación al contexto de las sociedades de cazadores-recolectores, tanto por lo que se refiere al proceso biológico como a las estructuras sociales, ya que éstos serian los responsables del proceso en sus fases iniciales.

Sin embargo, conviene recordar que la dirección tomada por los estudios sobre la neolitización fuera de España y Portugal abandonará đe forma progresiva prácticamente todas las consideraciones sobre el proceso biológico de la domesticación para demostrar que la agricultura no debe ser considerada como una "innovación", sino algo integrado en un marco de relaciones económicas y sociales más amplio, fundamentalmente en las sociedades de cazadores-recolectores, imprimiendo asi un nuevo giro a las investigaciones que implica un distanciamiento de las anteriores. Por un iado, los datos que reflejan actividades económicas pasan a incluirse casi de manera habitual, salvo excepciones, en todos los estudios, pero al ponerse el énfasis en interpretaciones que tienen en cuenta comportamientos observados en sociedades vivientes, se abandona el interés por los cambios experimentados por las especies de animales y plantas, disociándose ambos elementos integrantes del proceso. Pero éso ocurrirá algo más tarde. Sólo más recientemente se volverán a tomar en cuenta los procesos biológicos aunque desde otras perspectivas.

El interés por los aspectos económicos se hace mayor en esos años en nuestro país como lo demuestra el apartado dedicado al Neolítico por J. Maluquer (1973) en una His 
toria económica y social de España. Algunos de nosotros iniciamos nuestros trabajos sobre el Neolítico peninsular, centrados en esta problemática, en los últimos años de esa década. Sin embargo, es cierto que el acercamiento al problema se producirá, en mi caso, desde una óptica más cercana a la paleoeconómica inglesa, centrado en cuestiones relacionadas con la domesticación, en la valoración de las especies no silvestres identificadas en el registro arqueológico y en el papel jugado por elias en la economía.

Sin embargo, no podemos decir lo mismo por lo que respecta a Portugal que continüa con estudios de caŕ́cter más tradicional y así, J. Guilaine y $O$. Veiga Ferreira (1970) intentan una síntesis en la que distinguen hasta cinco grupos sucesivos de los cuales sólo los dos primeros se pueden atribuir al Neolítico antiguo en el sentido cronológico del término. Farinha dos Santos (1972) en cambio, plantea otro panorama más cercano al resto de la Peninsula. Con posterioridad, se han elaborado estudios parciales o sistematizaciones poco clarificadoras, siendo preciso llegar a la década de los ochenta o incluso a fechas aún más recientes para disponer de sintesis más actualizadas. Las investigaciones han estado dominadas sobre todo por el estudio del fenómeno megalítico. El uso además en la biliografia portuguesa del término pre-campaniforme. término vago e impreciso donde los haya, ha dificultado en gran medida el establecimiento de sucesiones más ajustadas.

Con la publicación de la Cueva de los Murciélagos de Zuheros (Córdoba) (VICENT y MUNNOZ, 1973), sus dataciones radiocarbónicas y el estudio de los cereales hallados en ella, la cronología de esta especie cerámica se eleva (.$^{\circ}$ milenio y principios del $\mathrm{IV} .{ }^{\circ}$ ). pero se plantean nuevos problemas. A. M. ${ }^{3}$ Muñoz los recoge en una comunicación presentada al VII. ${ }^{\circ}$ Congreso de Ia U.I.S.P.P. (1973), manteniendo para la almagra una fecha del Neolítico medio según los paralelos hallados y un origen en el Mediterráneo oriental, como era habitual.

La publicación del yacimiento francés de la Balma de Montbolo (GUilaINE, 1974) situado en los Pirineos orientales, introdujo la posibilidad de definir un nuevo grupo cultitral en la región catalana que se correspondía con un Neolítico antiguo evolucionado. fechado en torno al 4500 a. C. en el yacimiento citado. A propósito de este hallazgo se ofrecerá una nueva sistematización en la que las principales novedades vendrán dadas por la inclusión del grupo citado y del de Veraza que ocupará un Neolítico final, además de otras posiciones cronológicas.

Resulta evidente que hasta finales de los setenta los datos procedentes de análisis faunísticos o de macrorrestos vegetales no se incorporan a los trabajos de síntesis de modo que sean ellos lo que actúen como factor discriminante. Es preciso reconocer, no obstante, que será en la década de los ochenta cuando éstos se aceleren y permitan distintos enfoques y planteamientos. Sin embargo, esta circunstancia no alterará las posiciones anteriores, dado el carácter deudor del Neolítico peninsular con respecto al Próximo Oriente por lo que a las especies domésticas se refiere.

La obra de J. Fortea (1973) sobre los grupos epipaleolíticos de la fachada mediterránea peninsular marca un hito en la investigación del Neolítico y se perfila definitivamente como la interpretación que más éxito ha tenido hasta el momento presente. Se 
trata de la explicación dual defendida también por B. Martí y más recientemente por J. Bernabéu con otros matices, entre otros autores. La valoración de los cazadores-recolectores epipaleolíticos, siquiera a través de su producción lítica, se plantea por vez primera en profundidad en la bibliografia sobre el tema.

Esta explicación de la neolitización peninsular avanzada ya por otros investigadores cobró mayor vigencia a raíz de la publicación de la obra citada (FORTEA, 1973). En esencia, se trata de la defensa de un proceso asentado sobre una triple base en cuyas particularidades no me detendré puesto que es sobradamente conocido: las gentes neolíticas de la cexámica impresa cardial en cuya industria lítica será posible distinguir lo cardial puro (largas láminas retocadas con lustre de cereales en muchas ocasiones. taladros y quizá puntas de flecha con retoque en doble bisel invasor) y lo adoptado, consistente básicamente en geométricos (trapecios, escasos triángulos y medias lunas); las gentes del Epipaleolítico microlaminar tipo Mallaetes que pudieron experimentar una adaptación y fusión con el Epipaleolítco geométrico, recibiendo desde esta base la neolitización y las últimas fases del Epipaleolítico geométrico que constituyen un Epipaleolítico neoeneolitizado interior y serrano que se desarrolla paralelo al Neolítico cardial puro y ajeno a corrientes posteriores.

Esta misma base tripartita es la que defenderá B. Martí en alguna de sus obras (1978), aportando determinados matices que permitirán desarrollar el modelo o explica* ción dual. Siguiendo el mismo orden que J Fortea, este autor distingue yacimientos como Or y Sarsa (neolíticos puros) en los que podría señalarse la evolución completa de este Neolítico: el Epigravetiense de Mallaetes en el que no hay por tanto, un proceso de neolitización sino únicamente intrusión de cardiales y el yacimiento de Cocina, que muestra una perduración hasta momentos cercanos al Bronce valenciano con un gran predominio de animales no domésticos. Este autor define además, un momento de evolución del Neolítico más antiguo (tipo Or) que éi denomina Neolítico tipo Fosca e incluso una transición al Eneolítico.

Habida cuenta de que el Epipaleolitico microlaminar o Epigravetiense de Mallaetes no juega ningún papel en la neolitización, el esquema dual queda establecido para la investigación posterior a partir de los otros dos grupos.

El área levantina era entonces la mejor estudiada con diferencia. Si acaso podria señalarse que la sobrerrepresentación de trabajos sobre determinados yacimientos como Cova de l'Or, frente a la gran cantidad de materiales peor situados estratigráficamente o procedentes de estudios ya antiguos, pudo producir una visión menos ajustada del Neolítico de la zona.

Otras áreas van proporcionando también datos, en ocasiones poco definidos como en el caso del Pais Vasco (APELLÁNIZ, 1974 y 1975), aunque pronto se pudo contar con una obra de conjunto sobre los primeros testimonios de domesticación allí detectados (AlTUNA, 1980). En esa década se incorpora a la información existente documentación sobre las zonas aragonesa y meseteña, en la que el abrigo de Verdelpino (Cuenca) (FERNÁNDEZ MIRANDA y MOURE, 1975, y MOURE y FERNÁNDEZ MIRANDA, 1977) planteaba la cronología más elevada obtenida hasta ese momento para un yacimiento situado además 
en el interior de la Peninsula (6000 a. C.) con un Neolítico similar al del área valenciana (tipo Fosca), generando una polémica en la actualidad ya resuelta.

En todo caso, el orígen del Neolítico en estas zonas se suele plantear como una penetración desde la banda periférica, más o menos litoral, definiéndose el punto exácto en función de los materiales. Así, la aragonesa (cerámica cardial) estará vinculada a la catalana o levantina en el caso del Bajo Aragón, mientras que la Meseta se relacionará con Andalucía (aguadas a la almagra).

Un importante esfuerzo en la investigación del Neolitico andaluz lo supone la publicación de la obra de M. ${ }^{a}$ S. Navarrete (1976) sobre Andalucía orientai, en la que se proponia la procedencia del Neolítico inicial de Nerja a partir del foco levantino y un origen mediterráneo para el Neolítico medio y final de Pínar. Finalmente, la publicación del poblado de Los Castillejos de Montefrio (Granada) (ARRIBAS y MOLINA, 1979), fue de suma importancia para delimitar las fases finales del Neolítico andaluz.

En cualquier caso, de las obras aparecidas en la Península Ibérica hasta el inicio de los ochenta se desprende el interés por los problemas de autoctonia/aloctonía para el Neolítico peninsular, siempre con la mirada puesta en el foco próximo-oriental. Por otro lado, la única explicación que se habia formulado para la neolitización se basaba de nuevo en la tecnología (lítica), ya que persistía la visión de la domesticación como una invención tecnológica más llegada presumiblemente del exterior. Con lo que, de todos modos, el difusionismo, colonización incluida, continuaba constituyendo la hipó tesis más al uso.

El modelo dual ya claramente formulado asume estos presupuestos, considerando en todo caso, como ya he puesto de manifiesto. el papel jugado por los cazadores-recolectores epipaleolíticos en la neolitización, si bien será éste un papel pasivo, fundamentalmente receptivo. Este modelo sufrirá matizaciones a lo largo del tiempo que no harán variar lo fundamental, presentando en mi opinión, sin embargo, puntos débiles como tendremos ocasión de ver.

\section{LA INCORPORACIÓN DE LOS PI,ANTEAMIENTOS ANTROPOLOGICOS A LAS INVESTIGACIONES DE LA PREHISTORIA}

Los cambios teóricos experimentados por los planteamientos del Neolítico en general llevaron a la formulación de otras hipótesis como la demográfica (COHEN, 1981) en los inicios de los años ochenta, en un intento de buscar una explicación de validez general. La influencia de los enfoques de carácter antropológico, que a nuestro pais llegan a mediados de los setenta (ALCINA, 1975) con escasa repercusión de ese momento. condujeron de nuevo a una variación conceptual del Neolítico: un proceso de cambio que debe ser explicado en los diversos contextos y en el que como en otros, la idea de adaptación resulta fundamental. 
Las Teorías demográficas podrían encuadrarse en las de desequilibrio antes citadas. En mi opinión, el cambio que introducen radica en la constatación a través de la Etnografia de que los grupos de cazadores-recolectores tenían el suficiente conocimiento de animales y plantas como para poder haber desembocado en la domesticación; de que es necesaria una imperiosa razón para llegar a adoptar la agricultura que, en principio. implica mayor trabajo, una menor fiabilidad en los resultados y una reducción en la gama de alimentos y de que la agricultura no es una práctica poseedora de ventajas indiscutibles. Como contrapartida, los grupos de cazadores-recolectores están más idealizados.

En ese contexto, M. N. Cohen (1981) consideraba la presión demográfica como una explicación válida para todas las épocas. De hecho, es una de las más invocadas actualmente para explicar distintos procesos. En opinión de J. M. Vicent (1988, 48-50), a partir de la formulación de la teoria demográfica se produce una redefinición del concepto de domesticación que será el resultado a largo plazo de un cambio profundo: la sustitución de unos mecanismos demográficos por otros (de crecimiento expansivo a crecimiento intensivo).

D. Rindos proponía en 1984 (1990) un planteamiento alternativo para explicar el origen de la agricultura partiendo de presupuestos evolucionistas. Se trataría de un proceso coevolutivo (entre el comportamiento humano y el medio natural), que se iniciaria de forma casual y algunas especies se verían favorecidas por acciones no intencionales del hombre, continuándose a través de una dependencia progresiva entre todas las especies implicadas. Sin embargo, esta teoria, además de haber recibido abundantes críticas no ha tenido apenas repercusión, ya que hay una descontextualización excesiva del proceso histórico del orígen de la agricultura (VICENT en HERNANDO, 1994, 128), entre otras causas.

Pero lo más importante a mi juicio, es la nueva visión que sobre las sociedades de cazadores-recolectores se ha ido generando y la supresión de determinados tópicos sobre las evidentes bondades de la agricultura, que provocarian su inmediata adopción una vez alcanzado su conocimiento, así como también la percepción de la necesidad de ahondar en los procesos locales. La idea de invención lograda en focos privilegiados da paso a planteamientos distintos que cuestionan el difusionismo a ultranza antes fundamental en la explicación de la neolitización europea.

No obstante, en el año 1984, Ammerman y Cavalli-Sforza (1986) publican su conocido modelo del "frente u ola de avance" para explicar la neolitización de Europa que presuponía la migración de gentes oriundas del Próximo Oriente a un ritmo determinado ( $25 \mathrm{~km}$. por generación) y significaba de algún modo, la revalorización de las teorias đifusionistas. Según este modelo, la neolitización de Europa va acompañada de un flujo genético entre las poblaciones neolíticas próximo-orientales y las postpaleolíticas europeas. Se produce bajo la determinación de la difusión de las técnicas de producción de alimentos. Los testimonios que la soportan son: la relativa homogeneidad de los conjuntos arqueológicos correspondientes al Neolítico antiguo (la difusión tiene lugar al alcanzar una cierta madurez), la constatación de la ausencia de focos de domesticación en Europa y la homogeneidad de las especies domésticas (también se difunden al alcanzar 
su forma doméstica desarrollada) (AMMERMAN y CAVALLI-SFORZA, 1986) El escalonamiento de las dataciones radiocarbónicas mostraria la forma en que se produjo el proceso. Por lo que respecta a la Península Ibérica, tal modelo ha conocido mayor éxito en los momentos actuales que en el de su formulación. Sin entrar en otras consideraciones, ya que el modelo puede ser impecable como tal en su construcción y formulación, la base arqueológica de la que parte o dicho de otro modo, las variables elegidas son como mínimo parciales. Se generó en el año 1984 y evidentemente, el panorama ha variado desde entonces, tanto en el Próximo Oriente como en Europa. Pero ni siquiera en aquel momento tal explicación se correspondía con lo estrictamente observado en el registro arqueológico.

Conviene recordar que, fuera de nuestras fronteras, no todos consideraban adecuado el paradigma difusionista asi expresado para el Neolítico europeo y en esa línea, a mediados de los ochenta, G. Barker (1985) y R. Dennell (1987), exponian sus particulares visiones sobre el origen del Neolítico europeo y sobre el tratamiento del problema. Barker $(1985,11)$ señalaba cómo el contexto social en que se produce el paso a la producción de alimentos debía igualmente ser investigado. Por otra parte, recordaba que los testimonios existentes no reflejaban una clara dicotomía entre los cazadores mesolíticos y los agricultores neolíticos y que el tránsito suponía un fenómeno mucho más complejo que el que el modelo de la colonización dejaba entrever, por lo que era necesario un estudio regional que se iniciara con el de los yacimientos del Holoceno antiguo.

A su vez, Dennell criticaba también en 1985 (1987, 205-207) el modelo de la colonizáación, poniendo de manifiesto cómo los territorios de Europa y el Próximo Oriente no constituian entidades claramente separadas. Por otra parte, el segundo tampoco parecia hallarse tan densamente poblado como para justificar una migración, ni las culturas neóliticas del S. E. europeo son similares a las próximo-orientales, presentando además una acusada diversidad regional desde un primer momento. Además, tanto en Grecia como en Turquia los yacimientos del Holoceno inicial son escasos. Argumentaba también que la distribución de las especies no tuvo por qué ser la misma que en la actualidad y que los yacimientos de la Península balcánica no muestran el fracaso de los asentamientos que se suele producir en las colonizaciones. sino una ocupación de varias generaciones (tells de Bulgaria) En este caso, los territorios son los mismos que los elegidos hace cuarenta años en una economía planificada (DENNELL, 1987, 210), lo que supone un buen conocimiento de los territorios más adecuados para el cultivo. Creía, por último, que efectivamente pudo haber habido una difusión de especies domésticas, pero como productos de intercambio similares a la obsidiana, por ejemplo (DENNELL, 1987, 219).

Como conclusión defendía que, entre el 7000 y el 5000, se extenderia la economía agricola por muchas zonas de Europa mediante un doble mecanismo: a través de movimientos de pequeños colonos en áreas ocupadas por gentes que utilizaban los recursos tradicionales y, seguramente el más importante, por la adquisición gradual de técnicas y recursos útiles por parte de los grupos mesolíticos locales, que los asimilaron a las prăcticas existentes (DENNELL, 1987, 224). 
Pero los nuevos acercamientos planteados para la transición a la producción de alimentos desde la perspectiva de los cazadores-recolectores epipaleolíticos se halla presente en otras explicaciones. Recogiendo los conceptos acuñados por Woodburn en 1980 sobre economías de rendimiento inmediato o aplazado, se valoran ahora el almacenamiento (INGOLD, 1982 y 1985) y el sedentarismo como lo verdaderamente importante de la misma, pudiendo darse éstos antes o después que la agricultura que no pasa de ser otra innovación como la cerámica (TESTART, 1982) Curiosamente, los nuevos postulados conducen otra vez a viejos conceptos: la agricultura como innovación tecnológica. En el mismo sentido, B. Hayden (WENKE, 1984, 193-194) ve el nacimiento de la agricultura simplemente como una extensión lógica y natural de las tendencias que conducen desde el final del Pleistoceno a reorientar las estrategias desde la caza de gran talla a animales y plantas de pequeño tamaño, optando en este caso por recursos como las herbáceas ("r-selected") que permitirán un tipo de vida sedentario, útiles agrícolas, la estabilización del aprovisionamiento del alimento, la necesidad de cooperación del grupo y del almacenamiento común.

$T$. Ingold (1985), por su parte, opina que la división tradicional entre sociedades de cazadores-recolectores (o pescadores) y de agricultores y pastores debe ser sustituida por otras clasificaciones alternativas que incidan más en el nivel de relaciones sociales que en los progresos tecnológicos.

El inicio de estos planteamientos en opinión de $M$. Zvelebil (1986, 1), se sitúa en la consideración por j. D. G. Clark a partir de 1980 del Mesolítico como un preludio al menos, con lo que se introduce una situación más compleja que la simple difusión. A partir de ahí, otros autores como el ya aludido Denneil tratan el tema de la frontera agrícola y sús variantes, normalmente asociada a modelos de colonización aunque él no fuera precisamente un defensor de ella en sentido estricto, al menos inicialmente (ZVELEBIL, 1986, 10-11). El modelo de transición propuesto por Zvelebil y Rowley-Conwy es. en algunos aspectos, una extensión del anterior, tal como ellos mismos indican. El paso se produce a través de las distintas situaciones de frontera que pueden darse simultáneamente en el espacio geográfico (ZVELEBIL, 1986, 10-11), con tres fases sobradamente conocidas lo que excusa su análisis detallado: la de disponibilidad, la de sustitución que reviste dos formas (externa e interna) y la de consolidación que supone la etapa final de la transición (ZVELEBR, 1986, 12-13). Este modelo, relacionado sobre todo con el del "frente de avance", tendrá igualmente una destacada repercusión en las investigaciones peninsulares actuales más que en el momento mismo de su publicación.

Personalmente, creo que la variabilidad en el registro es tan sumamente amplia que los casos concretos superan la homogeneidad propuesta por los modelos. Ciertamente, es posible identificar algunos patrones pero en ocasiones cabe preguntarse si la multiplicación de modelos y sobre todo de clasificaciones hipotéticas no vienen de algún modo a encorsetar nuevamente una documentación enormemente rica.

En la década de los ochenta y hasta el momento actual, las investigaciones sobre el Neolítico peninsular han experimentado un impulso espectacular. Son varias las sintesis aparecidas en estos años, pero también se han multiplicado los análisis de polen, 
de macrorrestos vegetales, de fauna, antracológicos, ambientales de distinto tipo, asi como los estudios de cuitura material o de economía entre los que pueden situarse nuestros propios trabajos en este último campo (RuBio, 1981 y siguientes) Es necesario se- Galar también que desde los úitimos años de la década de los ochenta y hasta el momento presente incluso (1999), los planteamientos paleoeconómicos nacidos en momentos anteriores se han visto sobrepasados sin que, en ocasiones, se hayan agotado läs posibilidades sugeridas por ellos, por otros enfoques distintos de carácter teórico-explicativo encuadrados en un marco de raíz antropológica, el deseo de ir más allá en el campo de la Arqueozoologia por medio de disciplinas emanadas de ella como la Tafonoomía, los estudios de Etnobotánica o la utilización de las hueilas de uso en el material lítico para intentar clarificar cuestiones relativas a la domesticación de los cereales, entre otros. Los avances experimentados por los estudios prehistóricos en nuestro país, no sólo a causa del empleo del marco auxiliar, sino de los enfoques multidisciplinares e inćluso la elaboración de un marco teórico-metodológico nuevo, se hallan perfectamente acordes con los que encontramos en la investigación prehistórica general que por otra parte, nunca se ha perdido de vista ni se ha ignorado, se incorporasen o no determinados planteamientos a las tareas de investigación de cada momento, lo que a la inversa no siempre ha tenido la correspondiente contrapartida en la literatura científica fuera de nuestras fronteras.

En el año 1981, con la finalización de mi propia Tesis doctoral completaba el primer trabajo de conjunto sobre los aspectos socio-económicos del Neolítico peninsular, intentando analizar las eventuales tendencias económicas observadas en el registro arqueológico, pero también como se operaba el inicio de la economia de producción. Por esta razón, era inevitable pronunciarse sobre las cuestiones recurrentemente debatidas. En las conclusiones señalaba cómo, a mi entender, los grupos epipaleolíticos continuaron en algunos casos con sus modos de vida aún después de la llegada de algunos elementos que pudieron muy bien ser traidos por gentes nuevas: "Los recién llegados (nunca pensemos en oleadas numerosas, sino en un largo y gradual proceso de aculturación durante el que ambas partes intercambiaron conocimientos)... Que el origen ultimo de los recién llegados fuera próximo-oriental o ya europeo, mediterráneo, es algo que dilucidar. Personalmente me inclino por esta última posibilidad.. " (RuBio, 1981, 1405-1406).

Se supone que este intercambio de conocimientos tendria lugar porque, "los que ya vivian en estas tierras tendrían, como es lógico, una adaptación perfectamente lograda a un medio ambiental..." (RUBIO, 1981, 1422).

Del mismo modo, en este trabajo y en algún otro posterior, siempre bajo una óptica cercana a los planteamientos de la Escuela Paleoeconómica de Cambridge, ponía de manifiesto cómo podía atisbarse. según los testimonios existentes, un progresivo acercamiento entre especies faunísticas y grupos humanos y su control por éstos (casos de domesticaciones con elevada cronología, de domesticaciones en medios depredadores, de caza especializada y quizá de procesos de domesticación locales, necesitados muchos de eilos de confirmación que después no se ha producido) (RuBIO, 1981. 1435 y 1982). La consideración de parâmetros como el NMI en lugar del NR permitia afirmar que en 
el Neolítico antiguo, la fauna no doméstica y en concreto especies como el ciervo, constituían la base de la dieta, compensándose después la proporción entre animales domésticos y silvestres (RUBIO, 1982)

Si bien se recordaba que determinadas especies debian haber llegado forzosamente del exterior, debido a la ausencia de su agriotipo en la Península, esta difusión parecía haber sido rápida (RUBio, 1982, 189) Y en cualquier caso, desde el punto de vista de la economía, se consideraba imprescindible contemplar asimismo las estructuras de otros grupos no neolíticos que vivian al mismo tiempo en la Península Ibérica (RUBIO, 1982, 182)

Años después (RUBIO, 1989) reiterábamos que la aculturación ha constituido una explicación suficiente debido a la constatación de la aloctonía de ciertos elementos (algunas especies) Otros, en cambio, han confirmado su fabricación local no obstante su alto grado de elaboración. "A pesar de ello, en cierta medida podría explicarse la adquisición de técnicas de fabricación o el conocimiento de un equipo material distinto capaz de resolver los problemas que suponen nuevas actividades, a través de contactos o intercambios de información entre grupos extrapeninsulares y peninsulares que no implican, forzosamente, la liegada de gentes nuevas. No se niega, en ningún caso el desarrollo paralelo de técnicas autóctonas, locales, generadas por necesidades concretas o materias primas igualmente locales" (RUBio, 1989, 31) Por tanto, la diferencia con los planteamientos iniciales radicaba en que la aculturación defendida no necesitaba de la aportación de gentes foráneas ni tampoco que lo adquirido supusiera to predominante o lo más idóneo, habida cuenta de que los grupos peninsulares seguramente experimentaron con el objetivo de conseguir una adaptación mejor que les permitiera desarrollar su vida en las condiciones más adecuadas posibles.

En cuanto a las explícaciones propuestas por otros investigadores, podria señalarse un bloque más o menos homogéneo que incidía en los planteamientos del modelo dual, matizándolo e incorporando nuevos elementos y otras explicaciones, generalmente críticas a éste.

Dentro de ese bloque, B. Marti (1982) aclaraba que el llamado Neolítico "puro" "no hunde sus raices en nuestras tierras. Quiere ello decir, en consecuencia, que en este caso no podemos hablar propiamente de un proceso de neolitización" (MARTI, 1982, 98) Se basaba entonces, además de en los datos ya conocidos, en otros procedentes de Botiquería (Teruel), Costalena (Zaragoza) o la Cueva del Nacimiento (Jaén), asimilables a la tercera facies, que confirmarian a su juicio lo expuesto con anterioridad.

Por otra parte, se explicita claramente cómo esos elementos nuevos que se documentan en los yacimiento propios del Neolítico "puro" señalan la existencia de estímulos o contactos exteriores y una posible relación con el aumento del número de personas que componen estas comunidades, hallándose en conexión todo eilo con la aparición de la economía de producción (MARTí, 1982, 100).

Sin embargo, el autor no excluye la posibilidad de una neolitización dei Epipaleolítico geométrico anterior o paralela al Neolítico antiguo, debiendo considerar la relación de las comunidades neolíticas con el medio ambiente y el sustrato anterior. Aún así, con 
los datos del momento queda claro para él que la responsabilidad de la neolitización del Epipaleolítico geométrico se debe al Neolítico antiguo, siendo imposible hacerlo derivar je la tradición epipaleolítica y debiendo valorar la aloctonía de determinados elementos (MARTi, 1982, 101) Se refuerza con estos planteamientos la idea de la colonización como notor del cambio con el aumento demográfico consiguiente.

Con posterioridad, Fortea y Marti $(1984-85,193)$ vuelven sobre el tema para con-luir que se trata de un caso de desarrollo cultural dotado de múltiples mecanismos, sin zue se decanten por uno de ellos. El estudio comparativo de la industria lítica de Or y Zocina permitió a J. Juan-Cabanilles (1985, 29-30) deducir que el geometrismo observado en el primero de los yacimientos no se podia considerar una asimilación de los grupos epipaleolíicos locales sincrónicos, apoyando lo expuesto por los dos autores citados defensores del modelo dual.

Martí y Juan-Cabanilles (1987, 25-26 y 69-70) replantean otra vez dos años más tarde la dualidad de tradiciones haciendo hincapié, en esta ocasión, en la funcionalidad de los utiles de forma muy somera, aspecto fundamental a mi juicio para explicar el proceso en una dimensión más amplia. Los elementos de hoz constituyen el $12 \%$ en la industria lítica de Or, sugiriendo que ésta está orientada hacia los útiles compuestos y es en esencia una industria para hoces.

La valoración de los datos de otra indole se produce por Fortea y otros autores en el mismo año $(1987,590)$, considerando a partir del estudio de fauna de Cocina que la domesticación fue tardía y se introdujo desde un foco neolitizador independientemente de la evolución económica del yacimiento, lo que vendría apoyado por la inexistencia de macrorrestos vegetales.

Los mismos autores (FORTEA et alij. 1987, 608) destacan una vez más el modelo dual, preguntándose si podría considerarse el área valenciana como un área nuclear de segundo grado en la que las influencias externas estarian tamizadas por el sustrato, ya que únicamente en el caso de Or. Sarsa y Les Cendres se puede hablar de un Neolítico antiguo.

Por último, cabria señalar cómo este modelo condiciona o se refleja en estudios más concretos como los de la industria ósea, por ejemplo (VENTO, 1985, y RODANES, 1987) o en la interpretación del arte postpaleolítico (HERNÁNDEZ, FERRER y CATALÁ, 1988). Precisamente, la amplia aceptación del mismo justifica un análisis más detenido de la argumentación en que se basa.

Con anterioridad he expuesto mis dudas sobre la explicación dual (RUBio, 1989. 25 y 33 y 1993, 32-33), habida cuenta de que, a mi entender, no se perciben diferencias tan nítidas entre los rasgos de los grupos indigenas y los de las gentes foráneas (ocupación del territorio. hábitat, enterramientos, industria ósea, adorno, etc.).

La industria lítica ha constituido la base fundamental del modelo. Sin embargo, se echaria de menos la aplicación de un análisis funcional exhaustivo al conjunto de la industria de Or y de otros yacimientos con datos fiables, lo que permitiria una comparación en términos semejantes y una adecuada valoración de las actividades para las que 
fue fabricada. Como ya he tenido ocasion de observar (RUBio, 1989), se haria necesario también tener en cuenta los cambios a nivel diacrónico que se constatan en el registro de ambos tipos de yacimientos. Dicho de otro modo y asumido si se quiere que no se hallan emparentados, ¿por qué cambia el equipo material de estas gentes? ¿Qué actividades se desarrollan o dejan de desarrollarse para que éste se modifique? Por otra parte, incluso en los yacimientos estudiados se observa una variabilidad regional que se puede relacionar también con la de los usos del instrumental litico.

Las conclusiones se obtuvieron a partir del de tres yacimientos: Or, Botiqueria y Costalena en primera instancia y, por extensión, de otros tres: Sarsa, Nacimiento y Chaves, estableciéndose ulteriores comparaciones de carácter exclusivamente tipológico con algunos rnás. Sin embargo, incluso entonces, se conocia un número verdaderamente elevado de yacimientos, bien es verdad que con datos desiguales. De hecho, en el caso de los anteriormente señalados, únicamente tres cuentan con una secuencia estratigráfica importante. Unos y otros yacimientos dan la sensación de haber llegado al final con el tránsito al Eneolítico, por lo que al asentamiento se refiere.

El aumento demográfico sugerido en otro punto no parece defendible hasta ese momento preciso, dado que como el propio Martí señala, la cueva es un habitat propio de grupos reducidos y sería preciso realizar también una estimación, siquiera de forma hipotética, de la población precedente. En otro orden de cosas. icómo se explica la relación entre grupos en zonas de alta densidad como el macizo de Mondúver? Así pues. tanto para el estudio de la industria lítica como para el de otros aspectos era y es preciso volver a valorar también los yacimientos conocidos con anterioridad, aunque su estudio no estuviera destinado "a contestar preguntas", con objeto de constatar el volumen de ocupación del territorio y las supuestas diferencias de población. para poder construir una explicación sólidamente asentada.

No parece aquí, en cambio, tan trascendental la discusión cronológica dado que existen dataciones absolutas para situar ambos tipos de yacimientos.

Ciertos desfases como el del tipo cerámico (epicardial) de los yacimientos andaluces considerados herederos de una tradición epipaleolítica, en cuanto a la industria lítica, no se producen en otros igualmente deudores de esta tradición. por lo que la causa se podria buscar más bien en la situación de los primeros.

La valoración que en ocasiones se ha hecho de datos faunísticos, como el predominio de especies silvestres en los yacimientos de los grupos geométricos, considerándolo un indicador de la escasa presencia de la economía productora entre éstos, puede deberse a lo favorable del medio que hace innecesaria otra solución para la obtención del alimento y no a una division tajante entre agricultores y depredadores que, al menos en el contexto etnografico, dificilmente se encuentra. Por lo que respecta al estudio de fauna de Cocina, únicamente el NMI o los pesos (P) nos indicarian realmente el auténtico carácter de la explotación y cuáles eran las especies que proporcionaron el verdadero aporte cárnico a la dieta. Cabe recordar que, en el Neolítico de la cerámica impresa cardial, éste podría venir dado por especies como el ciervo y no, o no principalmente, por los ovicápridos, de modo que también en este caso, la caza es muy importante, habida 
cuenta de que incluso considerando únicamente el NR tampoco se aparta del modelo general. El predominio de especies silvestres en yacimientos como Botiquería podría explicarse muy bien por las condiciones especialmente favorables para la caza en la cuenca del Matarraña, visibles incluso en el momento actual.

Por lo que se refiere al arte postpaleolítico, supuesto reflejo de la misma dualidad, cabe señalar la escasa presencia del macroesquemático, muy localizada además, lo que dificulta la extensión de este modelo a otras áreas. En ese sentido, remito por ejemplo a los más recientes hallazgos de Aragón. Por lo mismo, parece preferible esperar a contar con un mayor volumen de datos (distribución de yacimientos de hábitat, de carácter simbólico, etc.). para poder atribuir de manera fiable, si procede, los distintos estilos artísticos a otros tantos grupos humanos.

I. Barandiarán y A. Cava, en un estudio sobre el Epipaleolítico y Neolítico en Aragón (1992), analizan el modelo dual, considerando también nuevos hallazgos y dataciones de la zona alavesa y de la atlántica francesa y llegan asimismo a la conclusión de que no se trata de algo tan claramente definido. La laminareidad de las industrias es igual entre Or y Sarsa y los yacimientos del Epipaleolítico geométrico interior, pero mientras que los primeros lo aplican a la recolección vegetal (láminas con huellas de uso), los segundos las emplean en un utillaje adecuado para la caza (hojas y hojitas retocadas entre otras manifestaciones) (BARANDIARAN y CAVA, 1992, 192). En ambos tipos de yacimientos se documentan los perforadores y los taladros. En Cocina IV, por otra parte, los geométricos se reducen a 9: 4 segmentos, 3 trapecios y 2 triángulos. La ausencia de microburiles puede deberse en su opinión a que no se aplicó esta técnica de extracción o a que el trabajo se desarrolló en otro lugar Las cerámicas cardiales de unos y otros son también semejantes (BARANDIARÁN y CAVA, 1992, 192-194).

Ya a nivel más general señalan cómo de las dos grandes entidades a que se han reducido todos los matices económicos (costa e interior), en el segundo caso los datos medioambientales son escasos. La consideración de la función/especialización en los útiles, la diferente conservación o los sistemas de recogida o clasificación son fundamentales a la hora de diferenciar tipos de yacimientos. En definitiva, a juicio de los autores señalados (BARANDIARÁN y CAVA, 1992, 194-195), las divergencias son cuantitativas (de presencia o ausencia también), pero sobre todo de proporciones.

En cualquier caso, en su momento tampoco todos los autores coincidian con la totalidad de esta explicación. J. Aparicio por ejemplo, era partidario de la convergencia, aún cuando a su juicio estuviera también justificada la defensa de la aculturación entendida como "un permanente y recíproco proceso (...) entre todas las poblaciones asentadas en las tierras de la cuenca del Mediterráneo occidental" (APARICIO, 1982, 81). En su opinión, podria probarse con los datos que poseemos la existencia de una etapa Protoneolítica, en la que se desarrollaría el auténtico proceso de neolitización y a la que seguirian dos horizontes neolíticos: 1, que no implicaria la llegada de gentes y seria fruto del largo periodo anterior, estando caracterizado por la cerámica cardial y otras decoradas), y II, ejemplificado en Cova Fosca (APARICIO, 1982, 93-96) 
C. Olaria (1986-87, 12-13) resaltaba también en aquellos años el papel de excesivo protagonismo otorgado al complejo geométrico. Para ella, era necesaria una valoración del carácter funcional de los útiles, considerando cada contexto, ya que además todos provenían de un estadio anterior. Por otra parte, la dualidad se basaba exclusivamente en la industria lítica y en la cerámica. Su propuesta era distinta: Cova Fosca representaría en realidad la neolitización, mientras que Or corresponderia a un Neolítico pleno (OlARIA, 1986-87, 14-15). Aún sin asumir la secuencia que dicha autora proponía, sin embargo sus observaciones sobre el modelo dual parecian acertadas por las razones que más adelante expondremos.

Esta misma investigadora señalaba también (1986-87) que el proceso de neolitización pudo ser consecuencia de tres factores: la evolución interna de la propia dinámica que llega a desarrollar plenamente los nuevos mecanismos del cambio económico neolítico; las influencias culturales de otros grupos más evolucionados transmitidas por contactos, préstamos o aculturación (transmisión "de vecino a vecino") o por la liegada de nuevas poblaciones con esquemas, nuevos también, económicos y tecnológicos de tipo neolítico.

En 1982. Morais Arnaud había ofrecido una visión alternativa del proceso de neolitización en Portugal en forma de dos modelos a comprobar, basados en estudios espaciales como los desarrollados por la Escuela Paleoeconómica o Paleoambiental de Cambridge y aplicados a la costa de Sines y al valle del Sado. El A, inspirado en el concepto de frontera de Alexander, se desarrollaría a través de cuatro fases. En la segunda de ellas llegarían "colonos" a la costa de Sines con una economía compatible con los mesolíticos, asentándose en un territorio no ocupado por éstos y estableclendo una frontera móvil que iría desapareciendo gradualmente hasta la absorción de los cazadores-recolectores en la última fase en la que se produciria la construcción de los primeros protomegalitos.

El modelo $B$ constaría, igualmente, de cuatro fases. En la segunda, los mesolíticos establecerian contactos con los navegantes venidos de otras zonas de la Península produciéndose una dualidad de actividades económicas (concheros estacionales y agricultura en los poblados de la costa). La desaparición de la frontera se produce también en las dos últimas fases, pero en la tercera los yacimientos del vaile del Sado forman parte ya de un territorio totalmente neolitizado. La variación estaria en el desarrollo de cada modelo en torno a la vieja cuestión: aculturación/colonización, incorporando técnicas de análisis diversas (modelos espaciales y de frontera social). Sin embargo, en lo fundamental puede considerarse una variante dentro de los planteamientos que venimos señalando.

J. Lewthwaite, por su parte, trató el tema de la neolitización en el Mediterráneo en repetidas ocasiones (1981, 1982, 1986 y 1987), como él mismo precisaba "pour extraire de sa coquille le "facteur social" (LEWTHWATTE, 1987). En su opinión, el Neolítico del Mediterráneo occidental no se ajustaba ni al modelo de un grupo intensivo de colonos agrícolas maritimos ni tampoco al de depredadores locales que adoptan la agricultura como una adaptación a presiones ambientales (LEWTHWAITE, 1981, 292). Existían además serias dudas, en su opinión, de que la cultura de la cerámica impresa constituyera una entidad 
homogénea clara (LEWTHWAITE, 1981, 304) Años más tarde, defendería que el papel de las islas mediterráneas fue critico actuando como "filtros" de la transición a la producción de alimentos (LEWTHWAITE. 1986, 53) Durante los dos primeros milenios del Postglaciar la población del Mediterráneo creció en proporción a los recursos en aumento por el desarrollo del bosque, comenzó a asentarse en las islas más grandes y cercanas (Córcega) y a provisionarse de recursos adicionales. Desde el 6000 a. C. los modos de obtención del alimento alternativos comienzan a avanzar hacia las márgenes $\mathrm{N} W$ y $\mathrm{S}$. E. de la región. Entre el 6000 y el 4000 a. C. la producción de alimentos se impone pero la tasa de adopción entre el este y el oeste y las islas y tierra firme varia según la estabilidad y complejidad de la estrategia de subsistencia depredadora indigena. Donde la población era escasa el proceso se ajusta a un modelo de colonización, en caso contrario se defiende la continuidad de la población (LEWTHWAITE, 1986, 64)

Este investigador opta por un modelo difusionista teniendo muy en cuenta las relaciones entre vecinos y analizando las diferencias en la transición a la producción de alimentos evidentes en el este y el oeste del Mediterráneo, donde la aparición del patrón de poblado campesino se retrasa considerablemente, asi como los mecanismos concretos que operan en cada zona (VICENT, 1997). Obviamente, algunas de estas afirmaciones no pueden sostenerse arqueológicamente, ya que el supuesto filtro insular no parece perfilarse tan claramente en el registro material. Pero, una vez más, la valoración en nuestro país del citado modelo ha tenido lugar, en fechas recientes y no tanto en su momento.

Así, no hace demasiado tiempo, J. M. Vicent (1997) al desarrollar ciertos aspectos de la explicación que propone y que veremos, recordaba cómo, en su opinión, el autor inglés fue el primero en contribuir a la reconsideración de los objetivos de la investigación de los años setenta y ochenta de los autores levantinos (ViCENT, 1997, 2). No obstante, la realidad es que la repercusión de este modelo en la investigación sobre la neolitización peninsular fue nula.

Podemos afirmar, según lo analizado, que a finales de los ochenta, el modelo dual seguía siendo el predominante aún con críticas y no será hasta más tarde cuando se propongan otros alternativos. En relación con esta situación, resulta evidente que la incorporación de los planteamientos antropológicos a las investigación del Neolítico peninsular se producirá más tarde que en otros lugares, manteniéndose el desfase general observado anteriormente para los enfoques derivados de la Nueva Arqueología que contaba ya con varias generaciones por lo que su configuración y algunos de los planteamientos iniciales se habian ya superado en ese momento.

\section{LAS TEORIAS Y MODELOS EXPLICATIVOS ACTUALES: DE NUEVO LA DIFUSIÓN}

Recientemente, las teorías generales sobre la aparición del Neolítico han sufrido un giro radical, si bien no han alcanzado el mismo éxito como explicación que las an- 
teriores. La Arqueología post-procesual y en concreto el enfoque contextual representado por I. Hodder ha proporcionado una de ellas, mientras que la segunda, cuyo autor (j. Cauvin) se enmarcaría, en principio, en otros planteamientos, ofrece una explicación basada igualmente en el mundo simbólico. Cabría resaltar, sin embargo, que ninguna de las dos ha tenido repercusión en nuestro pais ni tampoco un eco importante fuera de nuestras fronteras.

I. Hodder (1990) considera que la domus es la metáfora del cambio. La agricultura es una parte del cambio social e ideológico destinado a "domesticar" la sociedad como resultado del prestigio del dominio de lo cultural sobre lo natural. El control de las es pecies, teniendo el cuenta la etimologia del término domesticación, no era más que la tendencia contínua, inherente al hombre a hacer retroceder el dominio de lo salvaje frente a lo doméstico, siendo la casa el modelo y punto de partida. Por ello defiende la anterioridad de los cambios en el mundo simbólico y no en lo económico.

J. Cauvin $(1994,273)$, en una línea similar aunque con distinto enfoque, opina que el cambio fue primero cultural, aunque la manifestación más importante consistiera en la domesticación y la transformación de la naturaleza.

Del alejamiento de las Ciencias Naturales que, en los primeros estudios prehistóricos peninsulares se defendían como el contexto idóneo para su desarrollo, se cierra el círculo por el momento, abogando por los estudios multidisciplinares imprescindibles para la clarificación de determinados aspectos, aunque naturalmente el objetivo úitimo sea la reconstrucción histórica de la vida de los primeros agricultores de la Península Ibérica.

Por mi parte, señalaria una doble dirección en las investigaciones del Neolitico de la Península: la que acabo de indicar, a un nivel más empírico y la que aborda con nuevas perspectivas los planteamientos teóricos en el intento, en ambos casos, de proporcionar una explicación coherente al proceso de la neolitización peninsular. No obstante, de forma paralela, los estudios dedicados a la cultura material intentan esclarecer otros problemas por procedimientos tradicionales.

$\mathrm{Ni}$ que decir tiene que el estímulo experimentado en la investigación a nivel de Comunidades Autónomas ha tenido igualmente su repercusión en la bibliografia, tratándose en ocasiones de obras básicas también para la globalidad del estudio. Sin embargo, ni la cantidad ni la calidad de los datos son equiparables en todas las ăreas, presentando la regionalización de los datos otros problemas suplementarios que se evidencian por sí solos.

Como exponíamos en el título, el modelo dual (difusionista) se elige recurrentemente para explicar la neolitización peninsular, habiendo recibido un nuevo impulso en la década de los noventa. Sin embargo, ahora, se introducirán también nuevos planteamientos que generarán un bloque distinto constituido por el modelo que veremos a continuación y matizaciones posteriores.

La plasmación del giro tomado por las teorias explicativas de la neolitización peninsular se halla en el modelo defendido por J. M. Vicent (1990) que se vería esencialmente como el cambio de relaciones sociales de tipo abierto, perceptibles a través de la 
producción cardial, con una reciprocidad generalizada, a unas más cerradas vinculadas a restricciones sociales derivadas de alianzas entre grupos.

Dicho modelo parte de la base de que los acercamientos tradicionales no permiten explicar las transformaciones de los modos de vida humanos entre finales del Paleolítico superior y el ínicio de los periodos metalúrgicos. Implican éstas la aparición de nuevas formas de organización social y un punto de inflexión global en la historia humana (VICENT, 1990, 243). Como él mismo señala, se trata de explicar las deficiencias de la sistematización tradicional desde el punto de vista de un pensamiento histórico coherente (VICENT, 1990, 277).

Por otro lado, se observan determinados hechos que son perceptibles en los testimonios materiales como la continuidad arqueológica Epipaleolítico/Neolítico antiguo y un largo etcétera. Existen horizontes arqueológicos que él denomina interculturales como el cardial, el megalitismo o el campaniforme, más tardiamente.

La difusión de las tradiciones decorativas impresas hace pensar en un modelo de circulación de bienes en el que éstas servirian como medio para explicar obligaciones sociales o como un modelo de acumulación de capital o de prestigio social. Los paralelos del arte rupestre refuerzan esta idea y también la existencia de un orden simbólico elaborado (VICENT, 1990, 293). A lo largo del V. ${ }^{\circ}$ milenio existia la necesidad de establecer expresiones simbólicas de un cierto número de relaciones sociales y parte del "trabajo excedente" se invirtió en estas necesidades, en el marco de contactos entre grupos que posibilitarian la adquisición de nuevas especies (VICENT, 1990, 284).

El periodo post-cardial, por el contrario, ve la aparición de un intercambio a larga distancia que implica transacciones independientes de las obligaciones con los grupos vecinos y también la existencia de medios de acumulación de valor. La cerámica por otra parte, con una regionalización de patrones, ya no cumple la misma función social. Sin émbargo, el fenómeno arqueológico más claramente relacionado con la institucionalización de los medios de producción es el inicio de prácticas funerarias sistemáticas. Su relación con la constitución de grupos de filiación locales es clara (ViCENT, 1990, 284). Este hecho se evidenciaría en la cultura de los sepulcros de fosa, coincidentes en su opinión con la ocupación de poblados al aire libre en terrenos agrícolas. Seguramente, se hallará aquí la génesis del enterramiento colectivo (VICENT, 1990, 285).

El cambio se expresará en términos del paso de grupos que garantizan su subsistencia mediante la movilidad cíclica y la diversificación de la producción a otros que se apropian permanentemente del campo en torno a sus poblados (VICENT, 1990, 288).

El modelo defendido por J. M. Vicent resulta una explicación alternativa con especial énfasis en las cuestiones ideológicas y sociales que cormo él mismo señala, pueden ser difíciles de probar con el estricto dato arqueológico. A mi juicio, independientemente de la coincidencia o no con sus planteamientos, el modelo comentado resulta sumamente atractivo. Por una parte, se situia en el enfoque histórico, valorando la conducta humana y otros aspectos no por menos tangibles menos exentos de consideración. Por otra, sus planteamientos parten de la defensa de una continuidad de las poblaciones de 
cazadores-recolectores que evolucionan en sus modos de vida para resolver cuestiones fundamentales como la subsistencia. En tercer lugar, se plantea la relación entre grupos. evidente si examinamos la distribución de los hallazgos de especies domésticas y naturalmente de las primeras cerámicas, las cardiales, en el ámbito mediterráneo. ¿De qué otro modo puede explicarse esta similitud de ideas y rasgos o esa uniformidad presente en determinadas características del registro material a pesar de la variabilidad observada en ciertos aspectos, si no es mediante la comunicación? Nada de esto debe perderse de vista a la hora de ofrecer una explicación que dicho io anterior no puede buscarse aislada del resto. Discutible o no, este modelo ofrece además indudablemente un amplio horizonte para futuros trabajos de investigación.

Por mi parte, he considerado especialmente útil esta explicación desde su formulación y la he valorado al estudiar el adorno personal del Neolitico peninsular (RUBio, 1993). En mi opinión, este podría incluirse en redes semejantes a las defendidas para la cerámica (BARNETT, 1990) y en ese sentido, "no resultaria nada extraño un intercambio en régimen de reciprocidad como expresión de "necesidades" sociales y no sólo alimenticias..." (RuBIO, 1993, 50)

Esta situación se produciria fundamentalmente en el Neolítico antiguo con adiornos semejantes en todas las áreas y la constatación de contactos a través también de otros restos. pasándose quizá con posterioridad a una ruptura o a un cambio en esas relaciones debido a una mayor estabilidad económica que derivaría hacia una creciente seguridad paralela a una movilidad por el contrario decreciente. En ese momento más tardio, la regionalización es mayor en tipos y materias primas, hallándose además otras foráneas o fruto de una especialización extractiva y artesana como la variscita (RUBio, 1993)

Con posterioridad, el propio Vicent (1997) desarrolla su modelo partiendo de una crítica al dual y tratando de mostrar cómo se pueden abordar los mismos testimonios sin acudir a una explicación relacionada con la difusión. Para ello, valoraba la hipótesis del "filtro insular" ya citada, defendida por J. Lewthwaite. El modelo de Vicent, denominado como de "capilaridad", se basa en las relaciones de reciprocidad de los grupos postpaleolíticos mediterráneos que no superaron el nivel de bandas. Esta circunstancia produciría una forma de "conductividad" con flujos de bienes y beneficios sociales que servirían como vehículo de relaciones sociales. Estas propiedades de conductividad podrían ser isotrópicas, suponiéndose una situación relativamente estática de las poblaciones humanas. Este mecanismo de transmisión de la información se opone al difusionista "axial" La distribución de las cerámicas pudo estar ligada a aspectos no funcionales dando la impresión de áreas culturales. Las especies domésticas serian un recurso complementario que tendria que ver con un almacenamiento social. La Cova de l'Or pudo ser, en ese sentido, un lugar especializado. Las gentes neolíticas y su sustrato son las mismas en diferentes momentos de su evolución de subsistencia y actividades sociales.

Profundizando en este modelo, Rodríguez. Alonso y Velázquez (1995 y 1996) desarrollan uno basado en el concepto de percolación (flujo de un fluido en un medio poroso). De éste resulta "un sistema dinámico que se autoorganiza hacia un estado crítico, como consecuencia de la iteración de sucesos espaciontemporales a pequeña escala" 
(Teoria de la Criticalidad Auto-organizada) (RodRfGueZ, ALONSO y VELAZZUUEZ, 1996, 835) La propagación de las especies domésticas se explica en el marco de la Geometría Fractal. En el sistema interactivo resultante del carácter isotrópico antes citado, un acontecimiento da inicio a una reacción en cadena similar al efecto dominó. Si la estructura de los yacimientos se comporta como un fractal puede ser definida mediante un modelo matemático fractal que aproxime la red real de relaciones a distintas escalas entre la máxima (mediterránea) y la mínima (la individual) (RODRfGUEZ, ALONSO y VELAZQUEZ, 1996, 836-837) Por tanto, no es necesario recurrir a movimientos de población para la expansión de las especies domésticas a partir de una estructura relativamente estática de la población. Los únicos movimientos serían las prácticas exogámicas de los grupos (RODRIGUEZ, ALONSO y VELAZQZUEZ, 1996. 839).

La revalorización del paradigma difusionista y como consecuencia del modelo dual por J. Bernabéu. J. E. Aura y E. Badal (1993). proporciona un nuevo impulso a la explicación plasmada en el modelo del "frente de avance" Según estos investigadores, el proceso de neolitización presenta un carácter muy distinto en el Próximo Oriente (evolución que conlleva una progresiva dependencia de los grupos humanos de las especies domésticas) y en el continente europeo en el que se produciria la expansión de los sistemas agricolas y donde habría que tener en cuenta el contacto con poblaciones para las que estos recursos no parecían jugar ningún papel. La aparicion pues de estos sistemas en Europa será el resultado de la expansión demográfica de los agricultores y de la interacción entre éstos y los últimos cazadores-recolectores del Mediterráneo. El resultado es una situación compleja, regionalmente variable, donde la neolitización (adquisición de tecnología neolítica), se producirá con formas y ritmos diferentes, dependiendo, entre otras variables, del sistema de subsistencia adoptado por los mesolíticos (BERNABÉt, AURA y BADAL, 1993, 12) Ahora bien, estos autores opinan que el modelo dual, repetidamente invocado puede ser una respuesta adecuada a determinadas cuestiones que se derivan de la aceptación del modelo mixto de "frente de avance" (BERNABEU, AURA y BADAL, 1993, 245-246). El dual admite tres procesos distintos: la colonización y la aculturación directa e indirecta.

La constatación de este modelo en cualquiera de sus variantes únicamente puede decidirse sobre la base de estudios regionales desarrollados, lo que por el momento no es el caso en la Europa mediterránea. Partiendo de ciertas variables relacionadas con la tecnología y los sistemas de subsistencia ellos mismos elaboran diversos modelos. En este contexto, opinan que el arte postpaleolítico supondría un fenómeno paralelo al desarrollo por determinados grupos locales de una territorialidad creciente, coincidente con sistemas de subsistencia de rendimiento aplazado situados en la zona costera sobre todo, lo mismo que el megalitismo es considerado por determinados autores como el efecto que la agricultura-ganaderia tiene sobre las comunidades mesolíticas de la fachada europea (BERNABEU, AURA y BADAL, 1993, 231-260).

En esta línea, se propone un modelo que propugna la interacción de los Epipaleolíticos geométricos con componentes de un sistema cultural B (tecnologia, economía y asentamiento), con las gentes del Neolítico cardial con otro A (con las mismas variables). 
En este caso, la dualidad queda clara, en su opinión, a través de una secuencia que corresponderia a las fases de la ya conocida de Zvelebil y Rowley-Conwy.

Se precisa, en todo caso, que las matizaciones de cada una de las variables no siempre tienen su constatación en el registro arqueológico, por lo que es imposible probar determinados planteamientos.

A pesar de la valoración de aspectos distintos a los tradicionalmente tomados en cuenta podrian aducirse los mismos argumentos en contra que los expuestos para el modelo dual primitivo. No obstante, resulta evidente que la neolitización peninsular se enmarca perfectamente en un contexto general mediterráneo. Pese a ello, prácticamente todos los autores se refieren a neolitizaciones como muestra de la constatación de procesos que revisten formas distintas. Podría añadirse que, incluso la situación con respecto a los diversos agriotipos, es diferente con lo que quizá deberia variarse la explicación para otras regiones mediterráneas (área egea, por ejemplo).

Desde el punto de vista del análisis genético de las poblaciones humanas y también en clara relación con el mismo modelo del "frente de avance", Bertranpetit y Calafell (1992) han estudiado las de la Península Ibérica y en relación con ellas el proceso de neolitización. ya que, en opinión de estos autores, únicamente este fenómeno ha sido capaz de ocasionar efectos como los que veremos. Ellos parten de la base de que las características genéticas muestran una gran persistencia en el tiempo. Por otra parte, senalan cómo para que una migración tenga un impacto genético, tiene que haber una diferenciación genética entre las poblaciones que liegan y los nativos, debiendo constituir los primeros una parte importante de la población (CALAFEll y BERTRANPETIT, 1993, 736) El núcleo de su investigación consiste en una simulación demográfica. Se trata de un modelo estocástico (las distribuciones de probabilidad poseen un importante papel). expuesto en varias publicaciones (BERTRANPETTT y CALAFELL. 1992; CALAFELI y BERTRAN. PETT, 1993, y COMAS, CALAFELl y BERTRANPETIT, 1996) Los hechos observados en los resultados de su trabajo fueron interpretados con ayuda de la Arqueología, la Lingüística histórica, la Paleodemografia, la Antropología física y otras evidencias genéticas.

Como un primer factor, se determinó una dualidad entre la población vasca y el resto de la de la Península. Un segundo, fue la diferenciación entre la de la zona catalana con respecto a la del centro y sur La simulación tenía cuatro fases: la diferenciación preneolítica, la neolitización de la costa mediterránea, la expansión neolítica al resto de la Peninsula y un periodo postneolítico (CALAFEll y BERTRANPETT, 1993, 737). Según sus resultados, con anterioridad al Neolítico, la Península estaba habitada por pequeños grupos de cazadores-recolectores en unas condiciones que debieron producir un nivel relativamente alto de diferenciación genética por deriva de todas las poblaciones peninsulares.

La expansión del Neolítico se produjo desde el S.W. de Francia en el contexto de la general europea (BerTRANPETIT y CALAfELl, 1992, 44), por el Pirineo oriental. La aparición del Neolitico en este área duró unas cuarenta generaciones. La difusión a modo de "frente de avance" descle Cataluña por toda la franja costera mediterránea supone la búsqueda de tierras para cultivar por parte de poblaciones del N. E. y no de los inmi- 
grantes. La liegada al extremo sur de esta franja costera se produce en veinte generaciones al tiempo que se absorben las poblaciones de cazadores-recolectores. En la fase siguiente, tiene lugar la expansión al interior y a la costa atlántica en un lapso de tiempo de unos 500 años (unas cuarenta generaciones). A la zona vasca el Neolítico Ilega en la cuarta fase, que finaliza en los tiempos históricos, como una importación cultural y no demográfica. El ritmo de avance pudo ser de $1^{\prime} 5 \mathrm{~km}$ por año. El inicio de la expansión se produciría alrededor de los 5000 años a. C., la extensión por la costa se prolongaría hasta el 4000 a. C. y la llegada al oeste tendría lugar hacia el 3000 a. C.. Pero la población vasca continúa después con el aíslamiento que la caracteriza desde el Paleolítico superior, ya que una serie de factores culturales contribuyen a limitar la migración, si bien el intercambio génico no ha sido nulo. Zonas como Alava tendría unas características génicas intermedias al aprovechar las aportaciones llegadas por el valle del Ebro (COMAS, CALAFELL y BERTRANPETTT, 1996, 561)

Los resultados del modelo de simulación en opinión de los autores citados (BERTRANPETTT y CALAFELL, 1992, 45) sugieren una neolitización de la Península por Cataluña con un fuerte impacto demográfico que deja paso a un proceso de acuituración, sobre todo en áreas alejadas del origen y fundamentalmente en lugares de neolitización tardía. Sin embargo. como los mismos autores indican, los valores utilizados en la simulación no se pueden considerar validados porque el modelo funcione (CALAFELL y BERTRANPETTT, 1993, 742)

Este, como por otra parte el de la "ola o frente de avance", parte de premisas que no siempre se corresponden con la realidad arqueológica o incluso podría decirse que parecen selectivas, en cuyo caso sería conveniente explicar las causas de la elección. En primer lugar, para admitirlo habria que admitir previamente el modelo de Ammerman y Cavalli-Sforza. En segundo. la elección de las áreas ha sido un tanto arbitraria, ya que aunque algunas muestren una menor densidad de yacimientos, no están desprovistas de ellos y congresos como el de Gavá (1996) demuestran que este hecho se debe a lagunas en la investigación. Otras como Andalucia poseen un numero al menos tan elevado como el de las consideradas en el modelo y sus cronologias deberian de haber sido tenidas en cuenta. Por otra parte, si la navegación ha jugado un importante papel como se afirma por parte de los autores, el proceso parece haber sido bastante más complejo y desde luego cabría esperar que la venida de gentes (de producirse) habria tenido puntos de llegada diversos y no únicamente el Pirineo oriental. En otro orden de cosas, tanto el número de pobladores como su densidad son cifras basadas en datos etnográficos y por tanto se trata de estimaciones ideales. No queda claro tampoco porqué se absorben determinadas poblaciones indígenas y no otras, ni tampoco porqué, a la inversa, no lo son los recien llegados. La afirmación de que los parámetros de los grupos de cazadoresrecolectores se mantienen intactos en la expansión de los neoliticos hacia el sur concuerda mal con el supuesto impacto que justifica la construcción del modelo del que, por otra parte. puede que no sea posible nunca una demostración directa (CALAFELl y BERTRANPETIT, 1993, 745)

Paralelamente, la defensa del modelo dual se mantiene por parte de los autores que contribuyeron a su formulación. En una publicación más reciente (1994), B. Martí 
afirma que en la transición al Neolítico, la palabra clave será introducción y la dualidad cultural la problemática fundamental para cada una de las áreas, dualidad que él encuentra reflejada incluso en el arte (MARTI, 1994, 32 y 35) "La constatación de que durante siglos pudo mantenerse en amplias zonas una dualidad de población formada por quienes continúan con el modo de vida y la cultura material propias del Epipaleolítico de facies geométrica, y por aquellos otros que sincrónicamente desarrollan una nueva manera de vivir, con la agricultura, la ganadería y su muy diferenciada cultura material" (MARTI, 1994, 32). La aparición del Neolítico es descrita "como el resultado de la paulatina expansión de las comunidades neolíticas" (MARTf, 1994, 32).

Como ya he expuesto en páginas anteriores, no me resulta tan evidente la citada diferenciación de ambos equipos materiales. Según el propio Martí, la industria lítica que ha servido como base para estableceria es en ambos casos laminar (microlaminar para el Epipaleolítico geométrico) Los trapecios son dominantes en el conjunto cardial que, además, posee taladros y prácticamente ningún raspador o laminitas de borde abatido. Los triángulos predominan en el Epipaleolítico geométrico sincrónico, como demuestran "los niveles inmediatamente precerámicos" de Cocina, Botiquería y Costalena. En ambos casos, se dan soluciones y criterios diferenciados para las en esencia "armaduras de flecha". Los mismos argumentos señalados con anterioridad pueden ser aplicados en este caso, pudiendo deberse las diferencias a adaptaciones diversas y desde luego a la calidad de los datos y al número de yacimientos examinados.

Sería preciso evaluar no sólo el poblamiento neolítico como B. Marti $(1994,32)$ indica, sino también el epipaleolítico a la hora de defender cada modelo. Los datos de los estudios genéticos no pasan de ser un modelo de simulación por cierto más que discutible. En cuanto al arte, ya hemos expuesto las razones por las que nos parece arriesgada la atribución de su autoria a partir del esquema dual. Del mismo modo, resulta igualmente arriesgada la defensa de una territorialidad tan marcada que únicamente podrá ser resuelta con estudios espaciales de carácter global, afortunadamente ya en marcha. El yacimiento de Tossal de la Roca, citado por el mismo autor, sería justamente un ejemplo de esta problemática.

Por último, a juicio B. Martí, la diversidad cultural existente quedará explicada por la dualidad antes aludida y también por la existencia de fases estacionales y funcionales en el interior de las dos tradiciones cuyo proceso de convergencia se confundirá con el propio desarrollo del Neolítico de la periferia peninsular (MARTI, 1994, 37).

Recientemente, C. Olaria (1994) ha replanteado la cuestión de la neolitización del Pais valenciano desde el punto de vista de la calibración de las dataciones radiocarbónicas, al tiempo que expresa su desacuerdo con periodizaciones existentes. En su propuesta podrian distinguirse dos categorias de grupos (OLARIA, 1994, 21). los de tipo A con sistemas de rendimiento aplazado dentro de un marco de economía productiva territorial, enraizadas en un sustrato cultural epi-mesolítico con elementos de la cultura material neolítica (cerámica y avances en la explotación económica como el control, predomesticación o incipiente domesticación de algunas especies animales). Sería un Neolítico antiguo de cazadores-recolectores pastores (ca. 6000-5000 calBC). 
Los de tipo B son los grupos con sistemas productivos de base agrícola cerealista, sin conexiones con un sustrato cultural anterior, probablemente correspondientes a los modelos de "frente de avance", con cultura material innovadora y con economia plena de producción agricola y ganadera. Correspondería a un Neolítico antiguo de pastoresagricultores (ca. 5000-4500/4000 calBC)

Probablemente en la segunda de las etapas epipaleolíticas definidas (Mesolítico con industrias geométricas, datado entre 7000 y $6000 \mathrm{calBC})$, se darian los cambios sustanciales (OLARIA, 1994, 23).

Se constata un primer proceso de neolitización visible en la cultura material y en la economía (6000-5000 calBC) y una segunda etapa del Neolítico antiguo, con asentamientos plenamente neolíticos y economía productora entre el 5000 y el $4500 \mathrm{calBC}$. En un cierto momento serían contemporáneos.

Se percibe una convivencia de culturas en un marco muy variado (OlARIA, 1995, 26)

1 Asentamientos con cerámica y sin economía de producción.

2. Asentamientos con elementos neolíticos e incipiente domesticación y/o control de ciertas especies animales.

3. Asentamientos con elementos neolíticos y plena domesticación de ciertas especies.

4. Asentamientos con un conjunto rico y variado de elementos neolíticos y una economia productiva plena.

Entre el 4500 y el 4000 calBC se generalizan los cambios transformándose en el Neolítico medio (4000-3500 calBC) (OlARIA, 1994, 27). La transición entre el medio y final se sitúa ca. 3500-3000 calBC y el final/Eneolítico entre aproximadamente el 3000 y el 2500 calBC.

En esencia, se trata de nuevo de una explicación que gira en tomo a una supuesta dualidad en la que no se explicita el onigen de los elementos no enraizados en el sustrato anterior. Pero la particularidad más destacada es la interpretación del proceso como resultado de una aculturación en la que los grupos locales parecen ser los responsables del primer paso. Si ésto es asi, ¿cabe pensar que los elementos de la cultura material neolítica son autóctonos?

Sin embargo, es evidente que la variabilidad del registro material obliga a distinguir hasta cuatro tipos (y aún me sorprende que sólo se detecten cuatro) de asentamientos. Personalmente no lo expresaría como "convivencia de culturas", sino de grupos que desarrollan adaptaciones distintas dependiendo de múltiples factores que se han ido y se irán mencionando a lo largo de estas páginas. Sin embargo, la elección de una única variable: la cronología absoluta deja una vez más de lado la consideración de la totalidad de los datos arqueológicos. 
Pero C. Olaria y F. Gusi (1996) han expuesto una vez más sus críticas al paradigma cardial, siendo los puntos clave de las mismas la forzosa prioridad cronológica de este Neolítico, su origen, la excesiva valoración de la técnica decorativa cardial, lo temprano de la domesticación en yacimientos sin cerámica y los problemas que se derivan de la secuencia artística postpaleolítica. En cualquier caso, si consideramos estas valoraciones, puede sorprender un tanto parte de la secuencia ya analizada, establecida por C. Olaria a partir de las dataciones absolutas, ya que asume ciertos presupuestos (los referidos al tipo B). que tendrian mucho que ver con el paradigma objeto de crítica.

En una línea similar a la seguida por esta autora, Schuhmacher y Weniger (1995) distinguen igualmente varios (cinco) tipos de yacimientos con distintas combinaciones de elementos del Epipaleolítico y el Neolitico que, por cierto, se superponen en el este de la Península entre el 6500 y el 5500 calBC:

1 Yacimientos exclusivamente de cazadores (fauna silvestre y microlitismo).

2. Yacimientos de cazadores con cerámica (se añade la cerámica a los rasgos anteriores).

3. Yacimientos con testimonios de caza y pequeñas cantidades de animales domésticos (industria litica y cerámica).

4. Yacimientos con abundantes animales domésticos y escasos restos de caza (industria lítica y cerámica).

5. Yacimientos con abundantes animales domésticos, cereales y un papel importante de la cerámica. Los elementos propios de los cazadores son marginales.

A este patrón determinado en la zona mediterránea se puede unir el valle del Ebro y zonas de montaña adyacentes, así como el resto de Cataluña y en el sur las áreas premontañosas de la Meseta oriental y algunas de Murcia (SCHUHMACHER y WENIGER, 1995. 84). En esta amplia zona se diferencian tres grupos:

A. Epipaleolíticos: sus yacimientos muestran una subsistencia de cazadores-recolectores sin elementos neolíticos (8406-6049 calBC). A veces niveles de los del $A$ aparecen en el $B$ lo que indicarian un proceso de aculturación.

B. Epipaleolíticos con cerámica y/o animales domésticos: son fundamentalmente cazadores-recolectores con cerámica o con ceramica y domesticación de ovicápridos (6540-4719 calBC). La cerámica es lisa, impresa no cardial, incisa y con decoración plástica, pero también impresa cardial.

C. Neolíticos con cerámica sobre todo cardial y economía productora: animales domésticos y/o cereales (que pueden aparecer o no) (5956-4540 calBC). A partir de aqui se inicia ya la economía plenamente neolítica (SCHUHMACHER y WENIGER, 1995, 87-90). 
Con la excepción de Balma Margineda, todos los yacimientos de tipo $\mathrm{C}$ parecen de nueva fundación y se hallan en llanura o en la parte baja de las sierras colindantes. Sin embargo, las principales dificultades para su estudio residen en que se producen ciertas lagunas geográficas; de algunos se han excavado exclusivamente zonas restringidas y en otros las excavaciones son ya antiguas.

A partir de los datos estudiados se pueden elaborar tres modelos:

1 El de "los dos mundos" ("modelo étnico") que contempla la existencia de dos poblaciones diferentes: una en la costa (los neolíticos con cerámica, domesticación y cultivo de cereales) y otra en zonas montañosas del interior (epipaleolíticos con caza). Ambas poblaciones mantienen contactos e intercambio de productos (cerámica y animales domésticos).

2. El "del mundo único" con elementos del Neolítico, pero sin constituir una forma de vida asentada, sino con campamentos centrales desde donde en ciertas épocas todos o parte del grupo intentan aprovechar la caza, las materias primas y el pastoreo en campamentos estacionales.

3. El modelo "mosaico" que ofrece un amplio espectro de diferentes formas de subsistencia que, según las zonas, pueden ser bien neolíticos, bien cazadores. Proporcionan una imagen heterogénea con la utilización de campamentos temporales y el aprovechamiento de múltiples fuentes de subsistencia.

Sin embargo, para los autores es difícil defender una sola posición. El origen de la cerámica, el pastoreo y la agricultura habrian de ser tratados, a su juicio, independientemente de los modelos citados, pero la autoctonía sería la explicación más difícil de defender por la falta de agriotipos en la Peninsula. Es de destacar que a pesar de lo señalado afirman: "Si examinamos los yacimientos llamados neolíticos, su cultura material y su extensión, además del patrón de asentamiento en cuevas y abrigos no nos parecen tan distintos de los yacimientos con una subsistencia plenamente cazadora" (SCHUHMACHER y WENIGER, 1995, 94) La aparición del cambio en otras zonas en momentos distintos refuerza la idea de que no fue introducido por nuevos inmigrantes y que los grupos de cazadores indigenas integraron ideas nuevas en su tradicional forma de vida. Se decantarían por el modelo 3 como el de máxima posibilidad a la vista de los datos etnohistóricos y de los argumentos anteriores.

Schuhmacher y Weniger han percibido claramente la variabilidad existente en los testimonios arqueológicos aunque los yacimientos utilizados en el estudio hayan sido los habituales. Por otra parte, los tres grupos señalados corresponderian desde el punto de vista teórico a un proceso de aculturación o al modelo propuesto por Zvelebil y RowleyConwy Pero el establecimiento de los modelos finales sería más bien el reconocimiento de patrones a través de los datos analizados. Sin embargo, la afirmación que recogemos viene en cierto modo a relativizar el valor de algunas de las categorias que ellos estable- 
cen, aunque en mi opinión aciertan plenamente en el reconocimiento de unos rasgos que indiscutiblemente se hallan en el registro material.

J Zilhâo (1995) plartea la neolitización para Portugal con la llegada de la ceránica cardial y de las especies domésticas entre el $6800-6200 \mathrm{BP}$, a la zona norte de Extremadura portuguesa, mientras que las adaptaciones de cazadores-recolectores contemporáneas continuan hasta el 6000 BP en áreas más al sur en los estuarios del Tajo, Sado y Mira. El inicio de las economías agropastoriles está relacionado, a su juicio, con la llegada de colonos que, en interacción con los cazadores-recolectores locales, se halian en el orígen de la expansión subsiguiente completada mil años más tarde por todo el territorio portugués.

Los modelos de la domesticación de recursos locales o de la aparición de los nuevos mediante intercambios, basados en yacimientos del sur de España (Dehesilla y Nerja) y también Fosca más al norte o de Francia, muestran en su opinión importantes alteraciones en las secuencias estratigraficas que atañen a las fechas entre el 8000 y el 7000 BP (ZiLHÂO, 1995, 5). Esta circunstancia aconsejaría la aplicación de los correspondientes filtros tafonómicos. Recuerda el autor, por otra parte, la discontinuidad del asentamiento visible también en los yacimientos agrícolas italianos más antiguos.

El patrón de asentamientos ( tipo "enclave") y el escaso desfase entre las fechas de Francia y la Península Ibérica sugerirían un proceso de asentamiento inicial de pequeños grupos de navegantes en áreas que no estaban explotadas (o sólo marginalmente) por los grupos de cazadores-recolectores locales, seguido por una asimilación más o menos prolongada a un sistema económico nuevo. Este proceso que produjo rápidamente la amplia expansión de pequeñas colonias aisladas unas de otras, explicaria el patrón puesto de relieve por Guilaine y Veiga Ferreira de los estilos cerámicos en una amplia región: una similitud inicial en el cardial seguida por un marcado regionalismo en el epicardial o postcardial. La primera fase en la que se expandiría el nuevo sistema económico tendría lugar entre el 6800 y el $6400 \mathrm{BP}$ aproximadamente. La ruta del Danubio vería una rápida absorción de los cazadores-recolectores, mientras que en la mediterránea se daría un papel más activo de los mismos. Al final se habrian asimilado los grupos mesolíticos de la franja atlántica de Europa. En un segundo momento: 6000-5500 BP, habría desaparecido la frontera entre mesolíticos y neolíticos.

La aceptación de una colonización, marítima en este caso, implicaría de nuevo la dualidad que parece ponerse de manifiesto en la diferenciación que se hace también aquí entre neolíticos y mesolíticos que explotan los recursos acuáticos en Portugal. Faltaría por constatar esta situación de una manera fiable, ya que el Neolítico portugués adolece de una falta acuciante de estratigrafías y en mi opinión de prospecciones sistemáticas que realmente aportasen la verdadera dimensión de la ocupación del territorio, tanto en el Epipaleolítico como en el Neolítico. Del mismo modo, sería necesario tener un conocimiento más firme de los movimientos en busca de materias primas (recordemos que para los concheros de Muge se planteó la supuesta búsqueda del sílex en territorios situados bastantes kilómetros al interior), que aquí se consideran posteriores a la introducción de la cerámica y de las especies domésticas. 
Implicaría además esta explicación la resurrección de las dos vías defendidas hace años que difundian por Europa la economía de producción: una terrestre, la de la cultura de la cerámica de bandas, y otra mixta, la mediterránea.

Los dos tipos de modelos expuestos se basan principalmente en los datos existentés en el área levantina, ya que en ella parecen documentarse los testimonios de comunidades agrícolas con cronología más elevada por lo que resultaria evidente que se trata de un proceso claramente relacionado con la vertiente mediterránea en sus primeros momentos, en conexión es de suponer, con los restantes giupos que fabrican cerámicas con decoración cardial. Sin embargo, si tenemos en cuenta los datos más recientes del área andaluza en primer lugar y en segundo los que vamos conociendo de otras zonas, se pone de manifiesto la necesidad de buscar una explicación más completa que probablemente pueda hallarse en modelos como el defendido por J. M. Vicent.

Se comprueba fácilmente que los modelos elaborados hasta el momento presente han tomado como base los datos de áreas concretas, pero las explicaciones ofrecidas suelen aspirar a un alcance mayor. En este sentido, podría citarse algún otro propuesto fundamentalmente para Cataluña (MIRo y BOSCH, 1990) o para Andalucía (GUTiERREZ, PRIETO Y RUIZ, 1996)

Por lo que respecta al primero de ellos, los autores señalan que la comprensión de la extensión de la economia de producción al Mediteráneo occidental (y por ende a Cataluña) pasa forzosamente por el desarrollo a fondo del modelo teórico de aculturación, ya que en el planteamiento actual se perciben determinadas contradiciones. ¿De qué modo pueden superarse éstas?. El motor del cambio cultural habría de situarse en la transformación interna de las poblaciones epipaleolíticas y no en los estimulos foráneos y por otra parte, deberia incidirse en la captación y determinación de interacciones entre comunidades culturalmente diferenciadas (MiRÓ y BOSCH, 1990, 305). La traducción en el registro arqueológico sería la modificación de las pautas culturales con la incorporación de nuevas formas de producción y de nuevas tecnologías de las comunidades epipaleolíticas del VI. ${ }^{\circ} \mathrm{V}^{\circ}$ milenios. En su opinión, la expansión de la agricultura al Mediterráneo occidental no se puede supeditar a dos factores, el demográfico y el tecnológico, como se derivaria del concepto de frontera agricola tradicionalmente asociado a modelos de colonización/migración. Más bien habria una adopción gradual de técnicas y economia en función de las necesidades y estrategias de subsistencia de las poblaciones epipaleolíticas.

El proceso de aculturación, finalmente, sería visible en el registro arqueológico del área mediterránea peninsular a traves de la aparición de la cerámica (Botiqueria dels Moros, por ejemplo), la variación en la industria lítica (Cocina III y IV, entre otros) y la presencia de ovicápridos en medios epipaleolíticos (Filador N. IV), más recientemente (MIRÓ y BOSCH, 1990, 315-317). No obstante, como ellos señalan, lo importante es que ese proceso sería posible porque las comunidades epipaleoliticas ya habian desarrollado estrategias de intensificación por lo que la integración de nuevas técnicas y recursos encajaba perfectamente con su propio desarrollo (MIRO y BosCH, 1990, 317). 
En cuanto al segundo, pone en tela de juicio lo defendido con anterioridad por distintos autores que vinculaban el Neolítico de cerámicas impresas de Carigüela al catalán y levantino, distinguiéndose otro de cerámica a la almagra visible en Zuheros. Algunos yacimientos de excavación más reciente. Nerja entre ellos, llevaron a $P$. Acosta y a M. Pellicer a proponer un Neolítico fechado en el VI. ${ }^{\circ}$ milenio, con cerámicas decoradas no cardiales, además de cerámica a la almagra (en un momento no ínicial del mismo), que se suponía de orígen autóctono (extremo occidental de las Sierras Subbéticas).

Según los autores, la explicación del Neolítico andaluz no puede basarse en datos polémicos (cronologías elevadas o excavación de La Dehesilla) y sí en mecanismos como la difusión, la "ola o frente de avance" o como se prefiera denominarlos (GuTIÉRREZ, PRIETO y RUIZ, 1996, 628-629). Los nuevos yacimientos de superficie estudiados recientemente se hallarian en su opinión en zonas que consideran "progresivas" (por las facilidades para la práctica de la agricultura) frente a las "retardatarias" (por sus dificultades orográficas como focos de neolitización), donde se hallan Nerja, La Dehesilla y El Parralejo. Nuevos yacimientos como La Esperilla (Cádiz) permitirian, en cambio, relacionar este Neolítico al aire libre con la facies de cerámica cardial.

De nuevo, la difusión se elige como la explicación aparentemente más adecuada. Sin embargo, también una vez más, queda sin explicar suficientemente el Neolítico de cerámicas a la almagra sea cual sea su cronología.

A partir del análisis de los diferentes modelos sobre la neolitización peninsular, se evidencia lo expuesto en el título: el paradigma difusionista aparece recurrentemente en la investigación de la misma como la explicación considerada más adecuada. Dichos planteamientos pueden incluir o no la aportación de gentes y suponer la llegada de todo el conjunto de "novedades" neolíticas o únicamente parte de ellas (la economía productora y las especies involucradas y la cerámica, fundamentalmente). Curiosamente, los enfoques mantenidos en las teorias de carácter general sobre el orígen de la agricultura (y como consecuencia del Neolítico), no parecen tener una excesiva repercusión en las investigaciones peninsulares hasta momentos bastante recientes. Incluso aquellas más tradicionales relativas al continente europeo o al Mediterráneo en concreto han sido más valoradas con posterioridad que en el momento de su aparición.

Los planteamientos de carácter antropológico aparecen tarde en la literatura científica sobre el Neolítico peninsular aún cuando no sean desconocidos, quizá porque los enfoques más tradicionales se prefieren como una explicación más adecuada.

La elección de un único rasgo en el que basar estas afirmaciones ha sido igualmente común: la cerámica, la industria lítica (o las dataciones absolutas en los últimos años). como lo más representativo de las innovaciones tecnológicas entre las que, inicialmente y con los planteamientos de carácter antropológico después, ha sido incluida la agricultura.

A la inversa, la vuelta a antiguos enfoques aún con nuevos matices, resucita la cuestión de las vías de llegada: marítima y terrestre, planteada también ahora. Sin embargo, en mi opinión, se admita o se rechace la prioridad cronológica del Neolítico andaluz, en ningún caso se explica satisfactoriamente la delimitación de un ámbito con un 
registro material que difiere en ciertos rasgos y que, al contrario que el horizonte de la cerámica impresa cardial, no se encuadra en un ámbito mediterráneo más amplio. Posiblemente, en el marco de los modelos que atañen a las relaciones sociales podria hallarse una explicación más convincente. $\mathrm{O}$ alguna simplemente.

Ciertamente, las precisiones aportadas por determinados modelos difusionistas intentan explicar hechos como la irregularidad en la distribución del asentamiento sobre todo inicial. Sin embargo, la defensa de una colonización, de la llegada de navegantes o de una vía mixta, no contempla casi nunca el lugar de origen de los recién llegados, a no ser que implícitamente se considere el Próximo Oriente. Con todo, está por ver si la irregularidad observada no responde más bien a lagunas en la investigación de determinadas áreas.

La mayor o menor importancia otorgada al papel jugado por los cazadores-recolectores epipaleolíticos se plasma, en principio, en los modelos de aculturación como una aiternativa a los anteriores. Pero, evidentemente, es en otros como el de "capilaridad" y sus afines en los que ese papel pasa a primer plano. Estos parecen ser los más súsceptibles de aplicación para cualquier región peninsular y no sólo para la levantina, lo cual es sumamente importante dado el panorama que se va perfilando en muchas de ellas, como por ejemplo la Meseta.

Para concluir, cabría desear un mejor conocimiento de los grupos de cazadoresrecolectores en toda su complejidad para establecer con una mayor fiabilidad modelos o explicaciones de validez más ajustada. El difusionismo no parece haber permitido, a pesar de todo, interpretar satisfactoriamente toda una serie de procesos perceptibles en el registro arqueológico ni dar respuesta a interrogantes que aún continúan siendo planteados o a otros nuevos derivados de los datos más recientes. Asumiendo el condicionante impuesto por lo que sabemos hasta el momento presente sobre el origen de ciertas especies y considerándolo como un elemento más del proceso, parece necesario valorar la neolitización peninsular en sí misma buscando alternativas renovadoras a un paradigma que. en todo caso y en su forma más estricta, no siempre ni a todos ha llegado a convencer.

\section{BIBLIOGRAFIA}

AlciNa, J. (1975): En torno a la Antropología cultural Madrid.

Almagro. M. (1970): Prehistoria. Manual de Historia Universal. Madrid. I.

AitunA, J. (1980): Historia de la domesticación animal en el País Vasco desde sus origenes a la romanización. San Sebastián.

AMmerman, A. J., y CAVALLI-SFORZA, L. (1986): La transizione neolitica e la genetica di popolazioni in Europa. Turín.

ApARiCIO, J. (1982): "La neolitización y el Neolítico en Valencia (España)". Le Néolithique ancien méditertanéen. Montpellier. 81-96. 
APELLANiZ, J. M. (1974) Avance al estudio sobre el grupo de Los Husos durante la prehistoria con cerámica. Estudios de Arqueología Alavesa VI.

- (1975): El grupo de Santimamiñe durante la prehistoria con cerámica. San Sebastián.

ARRIBAS, A. (1961) "Le Néolithique de la Peninsule İberique". L'Europe à la fin de l'âge de la pierre. Praga, 489-492.

- (1968) "Las bases económicas del Neolítico al Bronce". Estudios de Economía Antigua de la Península Ibérica. Barcelona, 33-60.

ARribas, A, y Molina, F. (1979). El poblado de "Los Castillejos" en las Peñas de Los Gitanos (Montefrio, Granada). Campaña de excavaciones de 1971. El corte núm. I. Granada.

BARANDIARÁN, I.. y CAVA, A. (1992) "Caracteres industriales del Epipaleolitico y Neolítico en Aragón: su referencia a los yacimientos levantinos" UTRiLlA, $\mathrm{P}$ (Coord.): ARAGON/LITORAL MEDITERRANEO. INTERCAMBIOS CUITURALES DURANTE LA PREHISTORIA. Zaragoza, 181-196.

BARKER, G. (1985): Prehistoric farming in Europe. Cambridge.

BARNETT, W K. (1990). "Small-scale transport of early Neolithic pottery in the West Mediterranean". Antiquity 64, 859-865.

BENDER, B. (1978) "Gatherer-hunter to farmer" a social perspective" World Archaeology $10.2,204-222$.

Bernabéu, J.; AURA, J. E., y BADAl, E. (1993). Al oeste del Edén. Las primeras sociedades agricolas de la Europa mediterránea. Madrid.

BERNABO BREA, L. (1946). Gii scavi nella caverna delle Arene Candide (Finale ligure). Parte prima. Gli strati con ceramiche. Bordighera, I.

- (1956): Gli scavi nella caverna delle Arene Candide (Finale Ligure). Parte prima. Gli strati con ceramiche. Bordighera, II.

BERTRANPETIT, J., y CALAFELL, F. (1992): "Detecció dels efectes genètics de la neolitització en la població tbèrica actual". Estat de la investigació sobre el Neolític a Catalunya. Puigcerdá y Andorra, 43-45.

BiNFORD, L. (1968): "Post-Pleistocene adaptations" BiNFORD, S. R., y BiNFORD, R. L. (Eds.) New Perspectives in Archaeology. Chicago, 313-341.

Bosch Gimpera, P. (1932): Etnologia de la Peninsula Ibérica. Barcelona.

- (1961): "Los problemas del neo-eneolítico y el simposio de 1959" Zephyrus XII, 44-53.

- (1965): "La significación del neolítico circummediterráneo". Pyrenae I, 21-30.

- (1969): "La cultura de Almeria". Pyrenae 5, 7-93.

- (1974): Paletnologia de la Peninsula Iberica. Graz.

BRAIDWOOD, R. J. (1960). "The Agricultural Revolution" Scientific American 203, 130-141.

BRAIDWOOD, R. J., y WiLLEY, G. E. (Eds.) (1962): Courses towards urban life. Chicago.

CALAFELL, F., y BERTRANPETT, J. (1993): "A simulation of the genetic history of the Iberian Peninsula". Current Anthropology 34, 735-745. 
CAMPS, G. (1984) "Les relations entre I'Europe et l'Afrique du Nord pendant le néolithique et le chalcolithique" Scripta Praehistorica Francisco Jordá oblata. Salamanca, 187-208.

CASTILLO, A. del (1947) (1963). Neoeneolítico. MENÉNDEZ PIDAL, R. (Dir.) Historia de España. Madrid.I.I (parte IV), 489.714.

CAUvin, J. (1994) Naissance des divinités. Naissance de l'agriculture. Paris.

CIARK, J. D. G. (1952)' Prehistoric Europe: the economic basis. London.

COHEN, M. N. (1981): La crisis alimentaria en la prehistoria. Madrid.

Colominas, J. (1925) "Prehistoria de Montserrat" Analecta Montserratensia VI, 225-353.

COMAS. D., Calafeli, F. y BertranPETtT, J. (1996) "La detección del impacto genético de la expansión del Neolítico: estado de la cuestión". I CONGRÉS DEL NEOLfTIC A LA PENINSULA IBERICA (Gavá-Bellaterra, 27-29 de marzo de 1995). Rubricatum. Gavá, 1, 557-562.

CHILDE, V.G. (1936) (1972)' El origen de la civilización. Madrid.

DANiEL, G. (1987) - Un siglo y medio de Arqueologia. México.

DenNell, R. (1985) (1987) Prehistoria económica de Europa. Barcelona.

DIAZ-ANDRÉU, M., y MORA, G. (1995) "Arqueología y política: el desarrollo de la Arqueología española en su contexto histórico" Trabajos de Prehistoria 52.1, 25-38.

FarinHa DOS SANTOS, M. (1972): Pre-historia de Portugal. Lisboa.

FERNÁNDEZ, V. M. (1996) Arqueologia prehistórica de Africa. Madrid.

FERnÁNDEZ MiRANDA, M., y MOURE, A. (1975): "El abrigo de Verdelpino (Cuenca) Nuevo yacimiento neolítico en el interior de la Península İbérica" N.A.H. 3, 189-236.

FLANNERY, K. V (1969) "Origins and ecological effects on early domestication in Iran and the Near East" Ucko, P J., y DimBiebY, G. W. (Eds.) The domestication and exploitation of plants and animals. London, 73-100.

FLETCHER, D. (1956): "La doble faceta del neolítico hispano-mauritano en la región valenciana". C.I.C.P.P. (Madrid, 1954). Madrid, 415-417.

FORTEA, J. (1973) Los complejos microlaminares y geométricos del Epipaleolítico mediterráneo español. Salamanca.

FORTEA, J.. y MARTI, B. (1984-1985): "Consideraciones sobre los inicios del neolítico en el Mediterráneo español". Zephyrus XXXVII-XXXVIII, 167-199.

- et alii (1987): "Epipaleolítico y neolitización en la zona oriental de la Península Ibérica". Premières communautés paysannes en Méditerranée occidentale. París, 581-591

Gomez MORENo, M. (1933): "La cerámica primitiva ibérica". Homenagem a Martins Sarmento. Guimarâes, 125-136.

- (1949): "La cerámica primitiva ibérica". Miscelánea (Historia-Arte-Arqueología).. Madrid, 94-104.

GONGORA, M. de (1868) Antigüedades prehistóricas de Andalucia. Madrid. 
GuilAine, J. (1974): La balma de Montbolo et le néolithique de loccident méditerranéen. Toulouse.

Guilaine, J., y Veiga Ferreira, O. da (1970) ' "Le Néolithique ancien au Portugal". Bulletin de la Societé Préhistorique Française 67, 304-322.

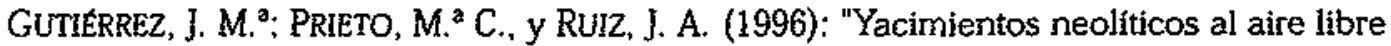
con cardiales: el asentamiento de Esperilla (Espera, Cádiz), propuesta de otro modelo de neolitización para Andalucía occidental". I CONGRÉS DEL NEOLITIC A LA PENINSULA IBERICA (Gavá-Bellaterra, 27.29 de marzo de 1995). Rubricatum. Gavá, 2, 627-638

HERNÁNDEZ PACHECO (1959): Prehistoria del solar hispano. Madrid.

HERNANDO. A. (1994): "El proceso de neolitización, perspectivas teóricas para el estudio del Neolítico". Zephyrus XLVI, 123-142.

HIGGS, E. S. (Ed.) (1972): Papers in economic Prehistory. Cambridge.

- (Ed.) (1975) Palaeoeconomy. Cambridge.

HIGGS, E. S., y JARMAN, M. R. (1972): "The origins of animal and plant husbandry" HIGGS, E.S.: Papers in economic Prehistory. Cambridge, 3-26.

HODDER, I. (1990) The Domestication of Europe. Oxford.

HOPF, M., y SchuBarT, H. (1965): "Getreidefunde aus der Coveta l'Or (Prov. Alicante)". Madrider Mitteilungen 6, 20-38.

INGOLD, T. (1982): "The Significance of Storage in Hunting Societies". Man 18, 553-571

- (1985): "The Significance of Storage in Hunting Societies". GAST, M., SIGAUT, F., y BEUTLER, C. (Eds.): Les techniques de conservation des graines à long terme. París.

JARMAN, M. R.; BAILEY. G. N., y JARMAN, H. N. (Eds.) (1982): Early European Agriculture. Cambridge.

JORDA, F., y ALCACER, J. (1948): La covacha de Llatas (Andilla). Valencia.

JUAN-CABANILLES, J (1985): "El complejo epipaleolítico geométrico (facies Cocina) y sus relaciones con el neolítico antiguo". Saguntum 19, 9-29.

LEE, R. B., y DE VORE, I. (Eds.) (1968): Man the hunter. Chicago.

LEISNER, V. (1967): "Die Verschiedenen Phasen des Neolithikums im Portugal". Neolithic Studies in Atlantic Europe. Palaeohistoria XII, 363-372.

LEWTHWAITE, J. (1981): "Ambigous first impressions: a survey of recent work on the early Neolithic of the West Mediterranean". Journal of Mediterranean Anthropology and Archaeology 1, 292-307.

- (1982): "Cardial disorder: Ethnographic and Archaeological comparisons for proble$\mathrm{ms}$ in the early prehistory of the west Mediterranean". Le Néolithique ancien méditerranéen. Montpellier, 311-318

- (1986): "The transition to food production: a Mediterranean perspective". ZVELEBiL, M. (Ed.): Hunters in Transition. Cambridge. 
- (1987): "Essai dans le cadre du Néolithique ancien méditerranéen pour extraire de sa coquille le "facteur social" Premières communautés paysannes en Méditerranée occidentale. París, 737-743.

LÓPEZ, P. (1988): "Historia de las investigaciones en tomo al origen del neolítico español". LOPEZ, P. (Coord.) (1988): EI Neolítico en España. Madrid, 59-64.

MaluQuer, J. (1973): La Prehistoria. VAzQuez de Prada, V. (Dir.): Historia económica y social de España. La Antigüedad. Madrid, I.

MARTI, B. (1978): "El neolítico valenciano". Saguntum 13, 59-98.

- (1982): "Neolitización y Neolítico antiguo en la zona oriental de la Península Ibérica". Le Néolithique ancien méditerranéen. Montpellier, 97-106.

- (1985): "Los estudios sobre el Neolítico en el Pais Valenciano y áreas próximas: Historia de la investigación, estado actual de los problemas perspectivas". Arqueología del País Valenciano: panorama y perspectivas. Anejo a Lucentum, 53-84.

- (1994): "Tradición cultural y procesos de cambio en el desarrollo del Neolítico peninsular". 6 Congreso Hispano-ruso de Historia. Madrid, 31 -38.

MARTI, B., y JUAN-CABANiLles, J (1987)- El Neolític valencià. Valencia.

- et alii (1987): "El Neolítico antiguo en la zona oriental de la Peninsula Ibérica" Premières communautés paysannes en Méditerranée occidentale. Paris, 607-619.

MARTINEZ SANTA OlaLla, J. (1946a) "Cereales y plantas de la cultura iberosahariana de Almizaraque (Almería)". Cuadernos de Historia Primitiva, I.

- (1946b): Esquema paletnológico de la Península Hispánica. Madrid.

- (1948): "La fecha de la cerámica a la almagra en el neolítico hispanomauritano" Cuadernos de Prehistoria Primitiva III.2, 95-106.

MiRO, J., y BosCH, J. (1990) "El procés de neolitització a Catalunya" ANFruns, j., y LLOBET, E. (Eds.). El canvi cultural a la Prehistòrla. Barcelona, 295-330.

MORA, G., y DIAZ-ANDRÊ, M. (Eds.) (1997): La cristalización del pasado. Génesis y desarrollo del marco institucional de la Arqueología en España. Málaga.

Morais ARNAUd, J. (1982). "Le Néolithique Ancien et le Processus de Néolithisation au Portugal". Le Néolithique ancien méditerranéen. Montpellier, 29-48.

Moure, A., y FERnANDEZ MiRANDA, M. (1977): "El abrigo de Verdelpino (Cuenca). Noticia de los trabajos de 1976" Trabajos de Prehistoria 34, 70-81

MUÑOZ, A. M." (1965): La cultura neolítica catalana de los sepulcros de fosa. Barcelona.

- (1970): "Estado actual de la investigación sobre el neolítico español". Pyrenae VI, 13-28.

- (1973): "El Neolítico español y sus relaciones mediterráneas". VII C. de la U.IS.P.P.. Belgrado, 2, 367-370.

- (1976): Consideraciones sobre el neolítico español. Barcelona, 27-40.

- (1997): "La cultura de los sepulcros de fosa: una sociedad neolítica". Espacio, Tiempo y Forma, 10, 265-278. 
NAVARRETE, M. ${ }^{a}$ S. (1976): La Cultura de las Cuevas con cerámica decorada en Andalucia oriental. Granada, 16-17

NIETO, G. (1959) "La cueva artificial de "La Loma de los Peregrinos", Alguazas (Murcia)" Ampurias 21, 189-244.

Olaria, C. (1986-1987) "Reflexiones en torno a la neolitización del Pais Valenciano" Cuadernos de Prehistoria y Arqueologia Castellonense 12, 7-27.

- (1994) "La problemática cronológica del proceso de neolitización en el País Valenciano: Una hipótesis de periodización" Quaderns de Prehistoria I Arqueología de Castello 16, 19-37

OlaRia, C.. y GuSI, F. (1996) "Cova Fosca. ¿Neolítico antiguo o Neolítico medio?. El paradigma cardial". I CONGRES DEL NEOLITIC A LA PENINSULA IBERICA (Gavá-BeIlaterra, 27-29 de marzo de 1995).. Rubricatum. Gavá, 2, 843-851

PARDO, P. (1996): "El desarrollo de la investigación sobre el Neolitico en la Península Ibérica: Planteamientos teóricos y metodológicos". I CONGRES DEL NEOLITIC A LA PENINSULA IBERICA (Gavá-Bellaterra, 27-29 de marzo de 1995). Rubricatum. Gavá, 2, 823-834.

PEIRO, I. y PASAMAR, G. (1989-90). "El nacimiento en España de la Arqueologia y la Prehistoria (Academicismo y profesionalización, 1856-1936)" Kalathos 9-10, 9-30.

PELLICER, M. (1962): Estratigrafia prehistórica de la cueva de Nerja. Excavaciones Arqueologicas en España, 16.

- (1964) El Neolítico y el Bronce de la cueva de la Carigüela del Pínar (Granada). Trabajos de Prehistoria, XV.

- (1967) Las civilizaciones neolíticas hispanas. GOMEZ TABANERA, J. M. (Dir.). Las raices de España. Madrid, 27-46.

PERiCOT, L. (1934) (1950): La España primitiva. Barcelona.

- (1967): Epocas primitiva y romana. Historia de España. Barcelona, I.

PIE. J., y RiBE, G. (1991) "Historiografía i Arqueología: El cas dels estudis sobre el neolític a Catalunya". ARCE, J., y OLMOS, R. (Coord.)- Historiografia de la Arqueologia y de la Historia Antigua en España (s. XVIII-XX). Madrid, 177-181.

PLA, E. (1961): "Actividades del S.I.P (1956-1960)". Archivo de Prehistoria Levantina IX, 275-328.

RindoS, D. (1984) (1990)' Los origenes de la agricultura. Barcelona.

RODANES. J. M. (1987): La industria ósea prehistórica en el valle del Ebro. Zaragoza.

RODRfGueZ, A.; Alonso, C., y VelAzQuEz, J. (1995) "Fractales para la Arqueología: un nuevo lenguaje". Trabajos de Prehistoria 52.1, 13-24.

- (1996): "La difusión occidental de las especies domésticas: Una alternativa a la "ola de avance". I CONGRES DEL NEOLITIC A LA PENINSULA IBERICA (Gavá-Bellaterra, 27-29 de marzo de 1995). Rubricatum. Gavá, 2, 835-842. 
ROMÂN, M. a de la Paz (1996): Estudios sobre el Neolitico en el Sureste de la Península Ibérica. Sintesis critica y valoración. Almeria.

RUBio, I. (1974): "Bases para el estudio de la economía agricola y ganadera en el neolítico hispano". CuPAUAM 1, 9-27.

- (1981): Aspectos socio-económicos del neolítico peninsular. Tesis doctoral inédita. UAM.

- (1982): "La economía de la Península Ibérica durante el Neolítico. Sus inicios". Le Nélithique ancien méditerranéen. Montpellier, 181-190.

- (1985): "Neolítico". NiETo, G. (Coord.) Los origenes de España". Historia General de España y América. Madrid, I-1, 211-254.

- (1986) "Economía neolítica en la Peninsula Ibérica" Revista Arqueologfa 60, 32-42 y 61, 6-12.

- (1988): "La economía de subsistencia en el neolítico hispano". LOPEZ, P. (Coord.) $E I$ Neolítico en España. Madrid, 337-418.

- (1989): "El Neolítico peninsular. Una interpretación de los datos arqueológicos". CuPAUAM 16, 11-41

- (1991): "Epipaleolítico y Neolítico" Veinte años de Arqueologia en España. Boletín de la Asociación de Amigos de la Arqueologia 30-31, enero-diciembre, 27-39.

- (1993) "La función social del adorno personal en la Península İbérica" CuPAUAM $20,27-58$.

- (1995). "Las periodizaciones del Neolítico peninsular Una perspectiva historiogrâfica". Verdolay 7, 31-39.

- (1995): "Algunas cuestiones del Neolítico peninsular. Datos para una revisión". Homenaje a $H$. Schubart. Boletín de la Asociación Española de Amigos de la Arqueologia 35, 79-96.

RUIZ ZAPATERO, G. (1988): "L'Escola Paleoeconomica de Cambridge" Corrents teorics en Arqueologia. Barcelona, 62-83.

RUSSELl CORTEZ, F (1953): "Aspectos do neolítico de Portugal". Archivo de Prehistoria Levantina 4, 81-104.

SAN VALERO, J. (1942): "Notas para el estudio de la cerámica cardial de la Cueva de la Sarsa". A.M.S.E.A.E. y P. XVII.

- (1945): El esferoide perforado de la Cueva de la Sarsa. Cartagena.

- (1946): El neolítico español y sus relaciones. Esquema de una tesis doctoral.

- (1950): "La Cueva de la Sarsa (Bocairente, Valencia)". Valencia.

- (1955): "El neolítico hispánico". IV C. de C.P.y P.. Zaragoza, 5-37.

SCHUBART, H., y PASCUAL. V. (1966): "Datación por el carbono 14 de los estratos con cerámica cardial de la Coveta de l'Or". Archivo de Prehistorla Levantina XI, 45-51.

SCHUHMACHER, T. X., y WeNIGER, G. C. (1995): "Continuidad y cambio. Problemas de la neolitización en el este de la Península Ibérica". Trabajos de Prehistoria 52.2, 83-97. 
SHNiRELAM, V. (1994) "Farming or fishing? on the unevenness of socio-economic development in neolithic times". 6 Congreso hispano-ruso de Historia. Madrid, 39-54.

SIRET, L. (1892): "La fin de l'epoque néolithique en Espagne". L'Anthropologie 4.

- (1893): "L'Espagne préhistorique" Revue des Questions Scientifiques.

TARRADell, M. (1959): "Problemas neoliticos" I Symposium de Prehistoria Peninsular, 45-67

- (1963) El pais valenciano del neolitico a la iberización. Valencia.

- (1964): "Para una revisión de las cuevas neolíticas del litoral andaluz". VIII C.A.N (Sevilla-Málaga, 1963). Zaragoza, 154-162.

TESTART, A. (1982): "The significance of food storage among hunter-gatherers; residence patterns, population densities and social inequalities". Current Anthropology 23, 523-537

TRIGGER, B. (1992): Historia del pensamiento arqueologico. Barcelona.

VENTO, E. (1985): "Ensayo de clasificación sistemática de la industria ósea neolítica de la Cova de l'Or (Beniarrés, Alacant). Excavaciones antiguas". Saguntum 19, 31-83.

VICENT, A. M. ${ }^{2}$ y MUÑoz, A. M. ${ }^{a}$ (1973): Segunda campaña de excavaciones. La cueva de los Murciélagos, Zuheros (Córdoba), 1969. Excavaciones Arqueologicas en España, 77.

VICENT, J. M. (1988): "El origen de la economía productora. Breve introducción a la Historia de las Ideas". LOPEZ, P (Coord.) El Neolitico en España, Madrid, 11-58.

- (1990): "El neolític: transformacions socials i econòmiques". ANFRUNS, J.. y LLOBET. E. (Eds.): El canvi cultural a la Prehistória. Barcelona, 241-293.

- (1997) "The "insular filter" hypothesis revisited" PRADOS, L.; GILMAN, A., y BalmuTH, M. (Eds.): Iberian/Sardinian Colloquium (Tufts University, Boston, 1991). Monographs in Mediterranean Archaeology, 671, 5-63.

WenKe, R. J. (1984): Patterns in Prehistory. Oxford.

WRIGTH, G. A. (1971): "Origins of food production in Southwestern Asia: a survey of ideas" Current Anthropology 12.4-5, 447-475.

ZLLAĀO, J. (1995): "The Spread of Agro-Pastoral Economies across the Mediterranean Europe: A View from the Far West". Journal of Mediterranean Archaeology 6.1, 5-63.

ZVELEBL, M. (Ed.) (1986): Hunters in transition. Cambridge. 